\title{
Error prone inference from respons time: The case of intuitive generosity
}

Citation for published version (APA):

Recalde, M. P., Riedl, A. M., \& Vesterlund, L. (2014). Error prone inference from respons time: The case of intuitive generosity. Maastricht University, Graduate School of Business and Economics. GSBE Research Memoranda No. 034 https://doi.org/10.26481/umagsb.2014034

Document status and date:

Published: 01/01/2014

DOI:

10.26481/umagsb.2014034

Document Version:

Publisher's PDF, also known as Version of record

\section{Please check the document version of this publication:}

- A submitted manuscript is the version of the article upon submission and before peer-review. There can be important differences between the submitted version and the official published version of record.

People interested in the research are advised to contact the author for the final version of the publication, or visit the DOI to the publisher's website.

- The final author version and the galley proof are versions of the publication after peer review.

- The final published version features the final layout of the paper including the volume, issue and page numbers.

Link to publication

\footnotetext{
General rights rights.

- You may freely distribute the URL identifying the publication in the public portal. please follow below link for the End User Agreement:

www.umlib.nl/taverne-license

Take down policy

If you believe that this document breaches copyright please contact us at:

repository@maastrichtuniversity.nl

providing details and we will investigate your claim.
}

Copyright and moral rights for the publications made accessible in the public portal are retained by the authors and/or other copyright owners and it is a condition of accessing publications that users recognise and abide by the legal requirements associated with these

- Users may download and print one copy of any publication from the public portal for the purpose of private study or research.

- You may not further distribute the material or use it for any profit-making activity or commercial gain

If the publication is distributed under the terms of Article $25 \mathrm{fa}$ of the Dutch Copyright Act, indicated by the "Taverne" license above, 


\section{Maastricht University}

María P. Recalde, Arno Riedl, Lise Vesterlund

Error Prone Inference from Respons Time: The Case of Intuitive Generosity

$\mathrm{RM} / 14 / 034$

\section{GSBE}

Maastricht University School of Business and Economics

Graduate School of Business and Economics

P.O Box 616

NL- 6200 MD Maastricht

The Netherlands 


\title{
Error Prone Inference from Response Time: The Case of Intuitive Generosity ${ }^{1}$
}

\author{
María P. Recalde \\ International Food Policy Research Institute \\ Arno Riedl \\ Maastricht University \\ Lise Vesterlund \\ University of Pittsburgh and NBER
}

\begin{abstract}
Response time is increasingly used to shed light on the process by which individuals make decisions. As mistakes may be correlated with response time it could, however, be misleading to use this measure to draw inference on preferences. To demonstrate we build on a recent literature, which uses response time to determine whether individuals intuitively are generous or selfish. Examining public good games researchers have shown that fast decision makers appear more generous than slow decision makers and this has been interpreted as evidence that generosity is intuitive and impulsive while selfishness is a calculated response (Rand et al. 2012; Nielsen, et al. 2014). Modifying the public good game to have an interior dominant strategy equilibrium we ask if the negative correlation between response time and giving is sensitive to the location of the equilibrium and whether it may result from mistakes. When the equilibrium is located below the midpoint of the strategy space we replicate earlier findings. However, when the equilibrium is located above the midpoint of the strategy space we get instead a positive correlation between response time and giving. While contribution distributions vary significantly by treatment for slow decision makers, these differences are not significant for fast decision makers. Fast decision makers are in both treatments more likely to make contributions that simultaneously lower individual and group earnings. We argue that the negative correlation between response time and giving rather than reflecting 'spontaneous giving', results from confused participants quickly selecting contributions that lie, on average, in the middle of the strategy space. Our results demonstrate that inference on preferences from response time requires that we take into account how mistakes are correlated with response time.
\end{abstract}

\footnotetext{
${ }^{1}$ We thank seminar participants at SITE (Stanford), SPI (University of Chicago), TIBER (Tilburg), ESA, ASSA, SABE, Erasmus University Rotterdam and the University of Pittsburgh for helpful comments.
} 


\section{Introduction}

Economists are interested in the choices people make. To better understand these researchers have begun to investigate the decision process that leads to choices. A series of physiological measures, such as brain imaging, eye tracking, measures of heart rate and skin conductance, have been used to gain insight into the factors that underlie people's decision making. ${ }^{2}$ Response time is another measure that increasingly is used to assess individuals' decision processes. The time it takes for individuals to make decisions has been used to predict individual choices between products, to predict indifference points, to more broadly draw inference on preferences, and to understand strategic thinking and behavior. ${ }^{3}$

The examination of response time has become particularly popular because the software used to elicit individual choices in the experimental laboratory automatically records the time it takes for participants to make decisions. Hence, data on response time is easily and cheaply acquired and researchers have unintentionally been collecting response time data for many of their past studies. With these data readily available researchers are quickly beginning to examine how response time correlates with individual choices. If we are to embrace this measure for inference on preferences it is, however, essential that we consider the extent to which the observed choices are indeed reflective of individual preferences and are not confounded by decision error. Specifically, the ability to draw valid inference from response time on preferences crucially hinges on the assumption that the frequency of mistakes is not correlated with the time it takes for an individual to make a decision. In this paper we study whether response time correlates with mistakes and whether this in turn hinders inference from response time on preferences.

To demonstrate how mistakes may taint the inference from response time we consider the recent literature examining whether individuals are tempted to be generous or tempted to be selfish. In extending the literature on dual selves and dual process reasoning to charitable giving the questions raised are: Is giving intuitive, impulsive, and emotional? Or, does giving require a slow, calculated, and cognitive decision? ${ }^{4}$ While it is important to determine whether individuals are predisposed toward generosity or selfishness, it is far from clear how we as researchers can answer this question. ${ }^{5}$ Existing evidence is scarce and contradictory. Using methods from

\footnotetext{
2 See e.g., Crawford (2008), Rustichini (2008), Smith and Dickhaut (2005), Caplin and Schotter (2008), Camerer, Loewenstein and Prelec (2005).

${ }^{3}$ See e.g., Rubinstein (2007), Chabris, Morris, Taubinsky, Laibson, and Schuldt (2009), Milosavljevic, Malmaud, Huth, Koch, and Rangel (2010), Schotter and Trevino (2012), Agranov, Caplin, and Tergiman (2013), Arad and Rubinstein (2012), and Caplin and Martin (2013).

${ }^{4}$ Central to models of dual selves is that decisions are influenced by an intuitive system which is responsible for impulsive, emotional, and rule-based choices, and by a deliberative system, through which calculated, cognitive, and controlled decisions are made (see e.g., Evans 2008; Kahneman 2003, 2011; Shefrin and Thaler 1988; Loewenstein and O'Donoghue 2004; Benhabib and Bisin 2005; Bernheim and Rangel 2004; Fudenberg and Levine 2006, 2012). Examples of studies asking whether generosity is intuitive or calculated are Martinsson, Myrseth, and, Wollbrant (2013), Kocher, Martinsson, and Wollbrant (2012), Kinnunen and Windmann (2013), and Kessler and Meier (2014). ${ }^{5}$ For example, inference on motives for giving depends on the extent to which individuals are intuitively generous. Vesterlund (2012) argues that a temptation to give generates the same comparative statics as those attributed to social pressure in DellaVigna, List, and Malmendier (2012).
} 
psychology and neuroscience some studies suggest that generosity is intuitive while others find evidence in favor of the deliberate generosity hypothesis. ${ }^{6}$ Rand, Greene, Nowak (2012) propose that response time can be used to determine whether individuals are intuitively generous. They argue that the intuitive decision can be inferred from decisions that are made quickly while the more calculated decision can be inferred from those that are made slowly and require time. To test this they examine contributions in a linear public good game and find that participants who make fast decisions contribute significantly more to the public good than those who spend more time making their decisions. From this negative correlation between response time and giving they conclude that cooperation is spontaneous and intuitive while greed is a calculated response. Similar conclusions are reached by Lotito, Migheli, and Ortona (2013) and Nielsen, Tyran, and Wengström (2014).

An important concern in using response time to draw inference on preferences is, however, that response time may be correlated with confusion or mistakes. ${ }^{7}$ This concern is particularly relevant in the linear public good game where mistakes can be erroneously identified as otherregarding behavior (Andreoni 1995; Houser and Kurzban 2002). In the classic linear public good game (VCM) $n$ individuals form a group and each allocate an endowment between a private and a group account. While a unit allocation to the private account generates a private payoff of 1 , a unit contribution to the group account secures a payoff of $r$ to each group member, where $1 / n<r<1$. To maximize own payoffs, it is a dominant strategy to place the endowment in the private account, whereas maximization of the group's aggregate payoff requires that the endowment be placed in the group account. ${ }^{8}$ An implication of this setting is that the core of the strategy space constitutes the entire range of available choices and, consequently, any (erroneous) deviation from the dominant strategy can be interpreted as consistent with otherregarding preferences. As quick erroneous deviations from the dominant strategy will attribute to the negative correlation between contributions and response times it is of particular importance to know if it is error prone participants who make fast decisions.

To explore whether error confounds the inference on intuitive generosity we conduct a laboratory experiment consisting of two public good games each with an interior equilibrium in dominant strategies. In one game, the equilibrium is below the midpoint of the strategy space, and in the other game it is above the midpoint of the strategy space. We refer to the first game as the "Low" treatment and the second game as the "High" treatment. Our design enables us to

\footnotetext{
${ }^{6}$ For example, Sanfey, Rilling, Aronson, Nystrom, and Cohen (2003), Ruff, Ugazio, Fehr (2013), and Kinnunen and Windmann (2013) show evidence consistent with other-regarding behavior being intuitive, while Knoch, PascualLeone, Meyer, Treyer, and Fehr (2006), Kocher, Martinsson, Myrseth, and Wollbrandt (2012), Fiedler, Glöckner, Nicklish, and Dickhert (2013) and Strang, Gross, Schuhmann, Riedl, Weber, and Sack (2014) show evidence consistent with other-regarding behavior being a deliberative choice.

${ }^{7}$ For evidence of correlation between response time and error see Rubinstein (2013). Kocher and Sutter (2006), Rubinstein (2007), and Agranov, Caplin, and Tergiman (2013) show that lower frequencies of dominated choices are associated with larger response times in beauty contest games.

8 Throughout the paper we use the term 'dominant strategy' to refer to payoff maximizing choices from a narrowly selfish perspective.
} 
characterize which choices are mistakes, and to determine whether the correlation between response time and giving is robust to the location of the equilibrium.

Using a between-subject design, we find evidence consistent with the Rand et al. result in the Low treatment. When it is a dominant strategy to contribute an amount below the midpoint of the strategy space, response time is negatively correlated with contributions. However, the correlation between response times and contributions is reversed in the High treatment. When the equilibrium is located above the midpoint of the strategy space, fast decision makers are less generous than those who take more time to decide, contradicting Rand et al.

Intriguingly, in both the Low and High treatments, fast decision makers are more likely to select contributions that lower individual and group earnings. By contrast, slow decision makers are more likely to contribute the equilibrium amount, and when they deviate from the dominant strategy they are more likely to contribute an amount that increases group earnings. Comparing the Low and High treatments we find significant differences in the contributions made by slow decision makers, while those made by fast decision makers are not distinguishable by treatment. These results show that the payoff differences associated with contributions in the Low and High treatments have little effect on fast decision makers and indicates that they are more prone to error than slow decision makers.

In two modifications of our experimental design we further investigate the role of error. First, to secure interior equilibria and to distinguish mistakes from welfare improving actions our initial design relies on a piece-wise linear payoff structure. This more complicated payoff structure may have increased the rate of error. We therefore ask whether similar results arise when the return to giving is constant as in the classic VCM. In a modified VCM treatment we add a private benefit for contributing to secure that full provision is the dominant strategy. In this High-VCM treatment we replicate our results and find that fast decision makers are less generous than slow decision makers. Second, to further assess mistakes we modify our initial piece-wise linear design such that the core is strictly interior to the strategy space and the boundaries are Pareto dominated. In these Low-Interior and High-Interior treatments we replicate all of our earlier findings and show that fast decision makers more frequently make contributions that are dominated from an individual as well as group perspective.

For all three variations of our High and Low design average choices by slow decision makers are very sensitive to the location of the equilibrium and easily distinguishable by treatment. By contrast choices by fast decision makers are far less sensitive, and are indistinguishable by treatment. Irrespective of whether choices made by fast decision makers result from mistakes, inattention, or indifference to incentives, the relative insensitivity to the location of the equilibrium indicates that choices made by fast decision makers are unlikely to purely reflect preferences over the available set of payoffs. 
In showing that the correlation between response time and generosity varies with the strategic environment, we argue that a negative correlation between response times and contributions, rather than being evidence of intuitive generosity, most likely results from 'confused' participants quickly selecting contributions that lie on average in the middle of the strategy space. Extending beyond the literature on intuitive generosity our results demonstrate that erroneous behavior must be accounted for if we are to use response time as an indicator of preferences.

\section{Related literature}

The use of response time to study decision making in economics is relatively recent. It started with the work of Wilcox (1993), who viewed response time as a proxy for decision cost and analyzed choices in risky environments. The subsequent literature has used response time to investigate the decision process employed by individuals, to make inferences about preferences, and to predict choices within and across domains. ${ }^{9}$

Chabris, Morris, Taubinsky, Laibson, and Schuldt (2009), for example, use response time to draw inference on preferences in binary intertemporal choice settings. They show that response time increases with the difference in net present value between options and use response time to predict discount factors. Milosavljevic, Malmaud, Huth, Koch, Rangel (2010), Krajbich, Armel, Rangel (2010), Krajbich and Rangel (2011), Krajbich, Lu, Camerer, and Rangel (2012) use response time to study drift diffusion models of stochastic choice, which make joint predictions about choices and the time individuals take to make decisions. Their work shows that response time decreases with the strength of preferences between options and can be used together with choice data to predict choices in binary and trinary food consumption settings. Schotter and Trevino (2012) use response times to predict indifference points in repeated binary global game settings. Clithero and Rangel (2013) use it to show that the drift diffusion model of stochastic choice can help improve out of sample predictions in binary food consumption settings. Krajbich, Oud, and Fehr (2014) study inefficiencies in the allocation of time in repeated choice settings and show that the drift diffusion model calibrated with food choice parameters can predict choices in other domains.

Rubinstein (2007) used response time to study the deliberation process employed by individuals and can be seen as the first who used response time to identify intuitive responses. He put forward the idea that fast choices are instinctive while slow choices are cognitive and analyzed the correlation between response times and choices in seven different strategic environments. ${ }^{10}$

\footnotetext{
${ }^{9}$ Further examining the decision process researchers have also investigated the effect of time pressure on choices (see e.g., Ibanez, Czermak and Sutter, 2009; Cappeletti, Güth, and Ploner, 2011; Kocher, Pahlke, and Trautmann, 2013; Reutskaja, Nagel, Camerer, and Rangel, 2011).

${ }^{10}$ See also Kahneman (2011).
} 
His work documents large variation in the types of choices associated with fast response times across strategic settings. ${ }^{11}$

Rand, Greene, and Nowak (2012) were the first to use response time with the idea to identify intuitive and deliberate actions in public good games. They analyzed the correlation between choices and the time individuals take to make decisions in a series of linear public good games (and binary prisoner dilemma games). ${ }^{12}$ Observing a negative correlation between contributions and response times they conclude that cooperation and generosity is intuitive while greed is a calculated response. ${ }^{13}$ Lotito, Migheli, and Ortona (2013) replicate the negative correlation between response times and contributions when endowments are asymmetric, and Nielsen, Tyran, and Wengström (2013) do so when the strategy method is employed. ${ }^{14}$ Brañas, Garza, Meloso and Miller (2013) document a negative correlation between offers to responders and the time proposers take to make decisions in the ultimatum game. ${ }^{15}$

In examining the correlation between response time and other-regarding behavior the literature has largely ignored the role of error. ${ }^{16}$ Specifically, the inference on preferences has not taken into account the possible correlation between mistakes and the time individuals take to make choices. Such correlation is of particular concern in the standard linear public good game where the entire set of available choices are in the core and any deviations from equilibrium can be rationalized by other-regarding preferences. If errors are uncorrelated with response time this is, of course, not an issue. However, it becomes an important confound if error is correlated with the

\footnotetext{
${ }^{11}$ In Rubinstein (2007) fast decisions are associated with fair outcomes in some settings, with equilibrium and efficiency maximizing choices in others, and with the use of strictly dominated choices in yet other environments. In many of the strategic settings investigated, however, focal choices coincide with fair, equilibrium, efficiency maximizing, and strictly dominated strategies. It is thus unclear what characterizes fast or intuitive choices.

${ }^{12}$ Analysis of non-strategic environments such as the dictator game has shown mixed results. Piovesan and Wengrström (2009) find a positive correlation between offers and the time individuals take to make choices within and across subjects. Cappelen, Nielsen, Tungodden, Tyran, and Wengström (2014) show instead that equal split offers are associated with faster response times than selfish choices.

${ }^{13}$ The authors also show that time pressure increases contributions in the linear public good game. Tinghög et al. (2013), however, note that the time pressure analysis presented in the paper is problematic because it excludes half of the observations from the sample. Tinghög et al. (2013) conduct a series of binary public good experiments in three different countries to reexamine the effect of time pressure on cooperation, and do not find a robust relationship. Rand et al. (2014) reanalyze data from 15 experiments that manipulate time pressure and show that the effect of time pressure is only sometimes positive and statistically significant. However, they also note that time pressure is never found to have a statistically significant negative effect on giving.

${ }^{14}$ Nielsen et al. (2014) use the strategy method to classify participants as free -riders, conditional cooperators, and other cooperator types. They show that free-riders are slower to make choices than other cooperator types. Their results could be driven by error if confused participants make fast choices that are arbitrarily coherent and increase with the contribution of others. See Ariely, Loewenstein, and Prelec (2003) for evidence of coherent arbitrariness in other settings.

${ }^{15}$ Rubinstein's (2007) analysis of response time and ultimatum game offers shows a negative correlation between response times and offers only when offers above the 50-50 threshold are excluded. Offers in excess of 60 percent of the endowment are associated with short response times, while offers between 50 and 60 percent of the endowment are associated with long response times.

${ }^{16}$ While drift diffusion models acknowledge that mistakes occur as part of the choice process, existing studies cannot identify mistakes explicitly and do not attribute the correlation between response times and choices to mistakes, but rather to the difficulty of choices measured through the differences in payoffs.
} 
time individuals take to make choices. If fast or slow decision makers more frequently are confused or inattentive, then response time will be a poor measure of preferences.

Existing evidence exploring whether mistakes are correlated with the time individuals take to make choices is mixed. Rubinstein (2013) studies the correlation between response times and mistakes in 10 decision tasks. He finds that mistakes are negatively correlated with the time individuals take to make choices when questions have a definitive right answer. Mistakes defined as violations of transitivity, however, are positively correlated with response time. Finally, mistakes defined as violations of consistency are not correlated with the time individuals take to make choices. Other studies have shown that the frequency of dominated choices decreases with individuals' response time in strategic settings. Sutter, Kocher, and Strauß (2003), for example, show that forcing subjects to make decisions quickly increases the rates of rejection in the first round of a repeated ultimatum game. Kocher and Sutter (2006) show that guesses in the beauty contest game increase with time pressure. Rubinstein (2007) shows that choices equal to or above the midpoint of the strategy space in the $2 / 3$ beauty contest game are associated with faster response times than any other strategy. Agranov, Caplin, and Tergiman (2013) use a strategytype method that maps choices over response time and show that while the guesses of strategic players decrease with response time, non-strategic players make average guesses that coincide with the midpoint of the strategy space and do not change with time.

Our study contributes to the literature by asking whether response time is a reliable indicator of individual preferences. We develop a strategic setting that allows us to identify mistakes and examine the extent to which error affects the observed correlation between response times and choices. While our study focuses on whether response time can be used to determine if individuals are intuitively generous or selfish, our results are also informative of inference from response time in other settings. Mistakes are likely to play a prominent role in unfamiliar strategic environments, hence inference on preferences from such settings require that mistakes and their distribution over time are accounted for.

\section{Experimental design}

In the classic linear public good game (aka voluntary contribution mechanism, VCM) an individual's private monetary payoff is maximized by contributing nothing irrespective of others contributions. That is, contributing nothing is a Nash equilibrium in dominant strategies when assuming narrow selfishness. A contribution of the entire endowment is needed to maximize the group's aggregate earnings. Moreover, in the VCM any deviation from equilibrium increases the payoffs of the other group members. This characteristic makes it difficult to determine whether an individual's positive contribution is made in error or is due to generous inclinations. To understand the role error plays in securing the negative correlation between response time and giving we therefore need to examine an environment where errors can be identified. 
To distinguish error from generosity we design a public good game where both the Nash equilibrium and the group-payoff maximizing contributions are in the interior of the strategy space. As in the classic VCM experiment we examine 4-person groups and secure the Nash equilibrium in dominant strategies. However, in contrast to the VCM our setting includes contributions that simultaneously lower the payoffs of the individual and the group, with the core as a subset of the strategy space.

In two different public good games we alter the location of the interior dominant strategy. In a Low treatment the equilibrium is below the midpoint of the strategy space and in a High treatment the equilibrium is above the midpoint of the strategy space. Using these treatments we ask whether the finding that fast decisions are more generous is robust to changes in the strategic setting. Characterizing behavior as fast and slow we also assess whether mistakes vary with response time and the extent to which mistakes contribute to the previously documented negative correlation between response times and contributions.

\subsection{Payoffs}

To secure an interior equilibrium we use a piece-wise linear payoff structure. Specifically, we extend the two-person framework of Bracha, Menietti, and Vesterlund (2011) to a four-person group. Participants are given a $\$ 10$ endowment, which they can contribute in $\$ 1$ increments to a group account. Contributions to the group account generate a constant and equal benefit to the other group members. The private benefit of contributing, however, is concave using a linear approximation. The participant's payoffs are given by the following function:

$$
\pi_{i}\left(g_{i}, G_{-i}\right)=\left\{\begin{array}{llc}
10+\alpha g_{i}+\sigma G_{-i} & \text { if } \quad 0 \leq g_{i} \leq g^{L} \\
10+\alpha g^{L}+\beta\left(g_{i}-g^{L}\right)+\sigma G_{-i} & \text { if } g^{L}<g_{i} \leq g^{H} \\
10+\alpha g^{L}+\beta\left(g^{H}-g^{L}\right)+\gamma\left(g_{i}-g^{H}\right)+\sigma G_{-i} & \text { if } g^{H}<g_{i} \leq g^{P} \\
10+\alpha g^{L}+\beta\left(g^{H}-g^{L}\right)+\gamma\left(g^{P}-g^{H}\right)+\delta\left(g_{i}-g^{P}\right)+\sigma G_{-i} & \text { if } g^{P}<g_{i} \leq 10
\end{array}\right.
$$

where $\pi_{i}$ denotes the monetary payoff individual $i$ receives from his or her contribution $g_{i}$ to the group account and the sum of contributions $G_{-i}$ made by the three other group members. Threshold contributions $g^{L}, g^{H}$ denote respectively the individual equilibrium contribution in the Low and High treatments, and $g^{P}$ the individual contribution associated with the unique grouppayoff maximizing outcome. Parameter $\sigma$ remains constant across treatments, while $\alpha, \beta, \gamma$, and $\delta$ vary. That is, across treatments we hold constant the benefit others get from an individual's contribution, while varying the individual's private return from giving. The specific parameters used in each treatment are shown in Table 1.

Table 1. Payoff function parameters by treatment

\begin{tabular}{llccccccc}
\hline \multirow{2}{*}{ Treatment } & \multicolumn{10}{c}{ Parameter } \\
\cline { 2 - 8 } & $\alpha$ & $\beta$ & $\gamma$ & $\delta$ & $\sigma$ & $\mathrm{g}^{\mathrm{L}}$ & $\mathrm{g}^{\mathrm{H}}$ & $\mathrm{g}^{\mathrm{P}}$ \\
\hline Low NE & 1.45 & -0.25 & -0.5 & -3.25 & 0.25 & 3 & 7 & 9 \\
High NE & 0.116 & 0.25 & -0.5 & -1.25 & 0.25 & 3 & 7 & 9 \\
\hline
\end{tabular}


Parameters were chosen to secure that the strategic settings fulfilled four requirements. First, there is an interior Nash equilibrium in dominant strategies, which varies by treatment. In our Low treatment the equilibrium contribution is $\$ 3$ and, thus, located below the midpoint of the strategy space. In our High treatment the equilibrium contribution is $\$ 7$ and, thus, located above the midpoint of the strategy space. Second, there is a unique interior group-payoff maximizing contribution of $\$ 9$, which is the same in both treatments. Third, equilibrium payoffs as well as the boundary payoffs associated with contributing $\$ 0$ and $\$ 10$ are held constant across treatments. Payoffs on the boundary are chosen such that the core contributions range from $\$ 3$ to $\$ 10$ in the Low treatment, and from $\$ 7$ to $\$ 10$ in the High treatment. ${ }^{17}$ Fourth, the cost of deviating from the equilibrium contribution toward the middle of the strategy space (between $\$ 3$ and \$7) is held constant in the two treatments. The strategic environments thus separate equilibrium contributions from both the boundaries and the midpoint of the strategy space, while holding key features of the environment constant across treatments.

Within each treatment, our design allows us to assess whether fast deciding participants more frequently make choices that decrease both the decision maker's earnings and the group's total earnings. Moreover, by comparing the pattern of contributions of fast and slow decision makers between treatments we can assess whether fast decisions are always more generous or whether the correlation between response times and contributions depends on the strategic environment. If mistakes are more frequently made by fast decision makers and if these mistakes on average result in contributions in the middle of the strategy space, then we would expect to find a negative correlation between response time and giving in the Low treatment but to find the reverse correlation in the High treatment.

We are primarily interested in documenting behavior in one-shot interaction. Yet, to assess stability, changes in behavior, and possible convergence we also examine the results of repeated interaction. Therefore, the decision making phase of our study consists of two parts. In Part 1 participants are matched in groups of four. Each group member makes a one-time contribution decision in a public good game. In Part 2 participants are informed that they are to play the same public good game for an additional ten periods, and that they will be re-matched after every period. Re-matching is random except that matching with the same participants twice in a row is impossible. Participants are at the beginning of the experiment informed that there will be two parts of the study and that only one part will count for payment. They are only informed of the content of each part immediately before reaching that part of the decision phase. That is, while contributing in Part 1, participants do not know that Part 2 is a repeated version of Part 1.

\footnotetext{
17 We also conduct experiments where $\sigma$ for $g_{i}>9$ is such that own- and other-payoffs decrease at $g_{i}=10$. See section 4.5.
} 


\subsection{Experimental procedures}

The experiment was conducted at the Pittsburgh Experimental Economics Laboratory (PEEL) at the University of Pittsburgh. Using a between-subject design we conducted four sessions of each of the two treatments. With 20 participants per session a total of 160 undergraduate students participated in the study. Each session lasted approximately 45 minutes with average payments being $\$ 22.50$ per subject (including a $\$ 6$ show up fee).

Upon entering the lab, participants were seated in a pre-marked cubicle, and were asked to provide informed consent to participate in the study. We then distributed instructions and read them out loud. The instructions provided a general description of the strategic setting. Participants were informed that there would be two parts of the experiment and that one would count for payment. They were given no information on what Part 2 would entail.

For Part 1 they were informed that they would be matched in groups of four and that they would each be given an endowment of $\$ 10$ that they could invest in $\$ 1$ increments in a group account. Participants knew that investment decisions would affect their payoffs and the payoffs of other group members, but were given no details on the actual payoff structure. They were told that payoff information would be presented to them via payoff tables displayed on the computer screen. The instructions explained to participants how they should read the payoff table and informed them that they would have to complete a tutorial before proceeding with Part $1 .{ }^{18}$

After completion of the instructions participants proceeded with the tutorial. Interfaces for the tutorial and for the decision making part of the experiment were programmed using z-Tree (Fischbacher 2007). The tutorial used a payoff table in which participants had two investment options. The payoffs in each cell were denoted using matrix notation. That is, no monetary payoffs were presented but rather combinations of letters and numbers (e.g., \$A11). Participants had to answer six questions in the tutorial, which asked them to identify the payoffs associated with different investment choices made by all group members. The tutorial allowed participants to enter incorrect answers, but presented solutions to ensure proper understanding.

Having completed the tutorial, Part 1 of the decision making phase began. Individual computer screens displayed the payoff table and asked participants to make a contribution decision. ${ }^{19}$ For a given average contribution made by the other three group members, the payoff table listed the individual's payoff of contributing between $\$ 0$ and $\$ 10$ and the average payoffs of the other group members. Time was recorded as the number of seconds it took participants to make a decision after seeing the payoff table. Time was not displayed on the decision screen. Once all contribution decisions had been made participants were shown a payoff screen informing them of their own contribution, the total and average contribution made by other group members, their own payoff and the average payoff of the other group members.

\footnotetext{
${ }^{18}$ For the instructions see the online Appendix.

${ }^{19}$ The payoff tables used in the experiment are presented in the online Appendix Table A1 and A2.
} 
Having completed Part 1, participants received instructions for Part 2. They were informed that Part 2 consisted of 10 periods of the same decision scenario as Part 1 . They were also informed of the random re-matching procedure and were told that if Part 2 was selected for payment only one randomly selected period would be paid. At the end of each period participants received the same feedback as in Part 1.

At the completion of the decision phase all participants were given a brief demographic questionnaire to determine their age, gender, nationality, year in college, and college major.

\section{Results}

In reporting the results of the experiment we begin by examining behavior in Part 1. For this part of the study we have a precise measure of the time it takes an individual to make a decision. We then proceed by discussing behavior in Part 2, checking the stability and convergence of the behavior observed in Part 1.

\subsection{Part 1: Contributions}

We have clear evidence that on average participants respond to the incentives in the Low and High treatment. Figure 1 presents a histogram of contributions by treatment. It shows that the modal contribution in each treatment is precisely the equilibrium prediction. 35 percent of participants in the Low treatment contribute $\$ 3$ and 36 percent of participants in the High treatment contribute $\$ 7 .^{20}$

In the Low treatment the average contribution exceeds the equilibrium prediction of $\$ 3$ (mean $=$ $\$ 5.06, \mathrm{p}<0.01)$, whereas in the High treatment it falls short of the equilibrium prediction of $\$ 7$ (mean $=\$ 6.57, \mathrm{p}<0.10) .{ }^{21}$ Hence, relative to the equilibrium prediction, on average, participants overcontribute in the Low treatment and undercontribute in the High treatment. Participants in the Low treatment, on average, contribute less than participants in the High treatment $(\mathrm{p}<0.01){ }^{22}$

\footnotetext{
${ }^{20}$ Of the 80 participants in each treatment the number of participants selecting the payoff maximizing strategy equals 28 in the Low treatment and 29 in the High treatment. This frequency of equilibrium play is higher than that usually documented for VCM. This suggests that our setting is not too difficult for participants to understand. The frequency of equilibrium play is however lower than that documented in Bracha et al. (2011), who use a piece-wise linear VCM similar to the one used here but with groups of 2 rather than 4 participants, and find a 60 percent frequency of equilibrium play. Isaac, Walker, and Thomas (1984) document a frequency of equilibrium play of 30 percent (across 10 rounds) in a linear VCM with various group sizes and various marginal per capita returns (19 percent in the first round of play when group size is four). For a general description of contribution behavior in the linear VCM see Ledyard (1995) and Chaudhuri (2011).

${ }^{21}$ Unless otherwise noted all tests are two-sided t-tests.

${ }^{22}$ A Wilcoxon Mann-Whitney rank-sum test provides $\mathrm{p}<0.01$. We also find statistically significant differences in the distribution of contributions across treatments (Kolmogorov-Smirnov $\mathrm{p}<0.01$ ).
} 
Importantly in both the Low and High treatments we see many choices that are dominated in the sense that a different choice simultaneously would increase payoffs to self and to others. Furthermore, some choices exceed the group-payoff maximizing contribution of $\$ 9$. Although contributions of $\$ 10$ benefit others, the individual marginal cost of giving $\$ 10$ rather than $\$ 9$ is so large that the group's aggregate payoff decreases.

Figure 1. Histogram of contributions by treatment, Part $1^{*}$

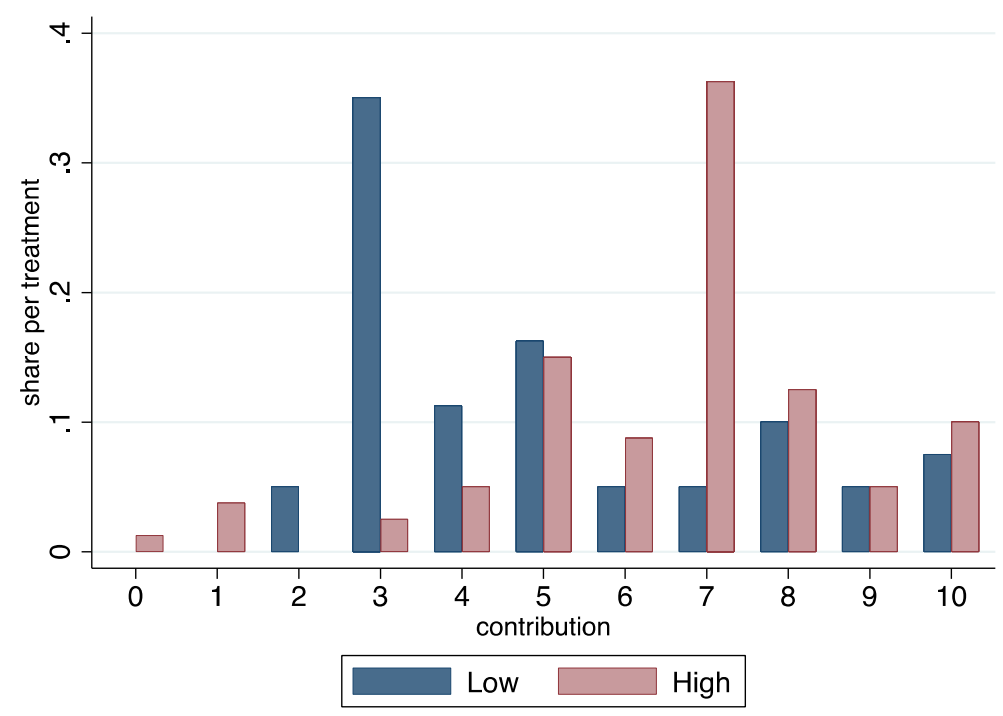

${ }^{*}$ The equilibrium contribution is 3 in the Low treatment and 7 in the High treatment. The group payoff maximizing contribution is 9 in both treatments.

Interestingly, when disregarding equilibrium play, the contribution distributions appear rather insensitive to treatments. Absent contributions of $\$ 3$ and $\$ 7$ we cannot reject the null hypothesis that the average of the remaining contributions are the same across treatments (the mean contribution in the Low treatment is $\$ 6.10$ and the mean contribution in the High treatment is $\$ 6.47 ; \mathrm{p}=0.479$ ). We can also not reject the null hypothesis that (absent contributions of $\$ 3$ and \$7) the two samples come from the same underlying distribution (Kolmogorov-Smirnov $\mathrm{p}=0.714$ ). The similarity in contributions is particularly striking when considering contributions of $\$ 4, \$ 5$, and $\$ 6$. These contributions are in the core in the Low treatment, but are outside the core in the High treatment. Despite the substantial differences in incentives the frequencies of these middle range contributions do not respond to treatments.

The rate of contributions that cannot be justified by generosity, and the similarity in offequilibrium contributions across treatments already suggest that choices may not be reflective of individual preferences over (own and others') payoffs. As we proceed to examine how contributions correlate with response time it is thus essential that mistakes be accounted for. Of particular concern is that overcontributions in the Low treatment and undercontributions in the High treatment result from error, and that the rate of these mistakes changes with response time. 


\subsection{Part 1: Response time and contributions}

The time it takes participants to make a decision varies substantially. Some participants spend as little as 4 seconds making a decision whereas others spend more than 3 minutes. There is, however, no evidence that response time differs by treatment (Kolmogorov-Smirnov $\mathrm{p}=0.490$ ). The mean and median response times of 50.61 and 41 seconds in the Low treatment and of 46.78 and 42.5 seconds in the High treatment do not differ statistically significantly between treatments $(p=0.497$; Wilcoxon Mann-Whitney rank-sum test $p=0.452$ ).

To test the hypothesis that response time is negatively correlated with giving we regress contributions on response time using OLS. ${ }^{23}$ Column 1 of Table 2 shows the results of the regression for participants in the Low treatment. The negative and statistically significant coefficient on response time is consistent with the existing findings from the VCM (e.g., Rand et al. 2012). When the equilibrium is located below the midpoint of the strategy space fast decision makers contribute more than slow decision makers. Although the size of the coefficient appears small, it indicates that participants who delay their decision by 1 minute on average contribute $\$ 1.14$ less than those who make a contribution decision right away.

Table 2. OLS regression of contributions on response time, Part 1

\begin{tabular}{lccc}
\hline \multirow{2}{*}{ Dep. Var.: Contribution to group account } & \multicolumn{3}{c}{ Treatments } \\
\cline { 2 - 4 } & $\begin{array}{c}\text { Low } \\
(1)\end{array}$ & $\begin{array}{c}\text { High } \\
(2)\end{array}$ & $\begin{array}{c}\text { All } \\
(3)\end{array}$ \\
\hline Response time & $-0.019 * *$ & $0.016^{* *}$ & $-0.019^{* * *}$ \\
& $(0.008)$ & $(0.006)$ & $(0.007)$ \\
High & & & -0.205 \\
& & & $(0.598)$ \\
High x response time & & $0.035^{* * *}$ \\
Constant & $6.024 * * *$ & $5.819^{* * *}$ & $6.024 * * *$ \\
& $(0.469)$ & $(0.376)$ & $(0.443)$ \\
\hline Total effect response time: High & & $0.016^{* *}$ \\
N & & & $(0.007)$ \\
\hline Note: Standard errors in parentheses. $* \mathrm{p}<0.10, * * \mathrm{p}<0.05, * * * \mathrm{p}<0.01$.
\end{tabular}

The correlation between contributions and response times is, however, sensitive to treatment. Column 2 of Table 2 shows that in the High treatment the correlation is positive and statistically significant. The coefficient on response time is of similar magnitude as that estimated in the Low treatment but of opposite sign. A participant who delays the decision by 1 minute will on average contribute $\$ 0.96$ more than someone who makes a contribution right away. Column 3 of Table 2 pools the data from the two treatments to test whether treatment effects are statistically different.

23 Tobit regressions that take into account the censoring at $\$ 0$ and $\$ 10$ are presented in the Appendix and provide similar results. 
Using a difference-in-difference regression of contributions on response time and treatment column 3 shows two things. First, the insignificant coefficient of the dummy variable High (1 if treatment is High, 0 otherwise) indicates that the mean treatment effect is not significantly different from zero. Second, the positive and highly significant coefficient of the interaction between the dummy High and response time (High x response time) shows that the correlation between contribution and response times differs between treatments. While for fast decision makers there is limited difference in contributions in the Low and High treatments, this difference increases with response time. Thus, the treatment differences seen in Figure 1 result from slower decisions.

The results reported in Table 2 demonstrate that the strategic environment can determine whether fast decision makers are found to be more generous than slow decision makers. Looking at contributions by response time it becomes clear why the comparative statics reverse with treatment. Figure 2 presents a scatterplot of response times and contributions by treatment. The solid vertical line indicates the location of the equilibrium contribution ( $\$ 3$ and $\$ 7$ in the Low and High treatment, respectively) and the dashed vertical line indicates the location of the contribution that maximizes the group's total earnings ( $\$ 9$ in both treatments). The horizontal line indicates the median response time of the pooled sample (41.5 seconds). For the remainder of the analysis we refer to participants who use less than the median response time to make a decision as being fast decision makers and to participants who use the median response time or more to make a decision as being slow decision makers. Thus, choices by fast decision makers are shown below the horizontal line and those by slow decision makers above the horizontal line.

Figure 2. Scatterplot of contributions and response time by treatment, Part 1
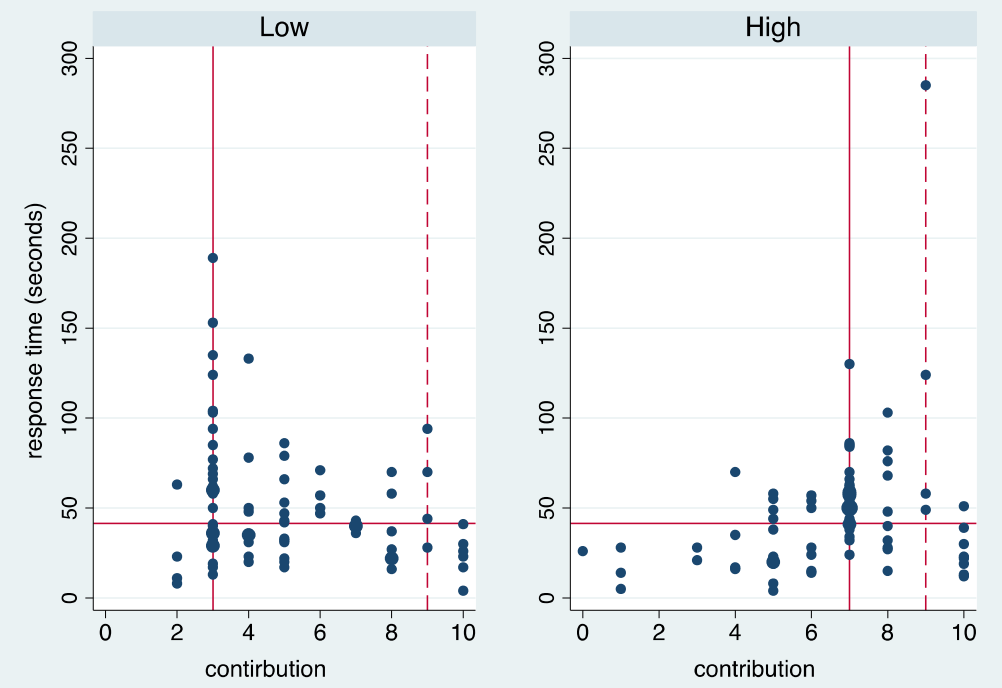

Note: The solid vertical line indicates the Nash contribution, the dashed vertical line indicates the efficiency maximizing contribution, and the solid horizontal line indicates the median response time of the pooled sample (41.5 seconds). 
Inspecting the lower segments of the graphs in the two panels of Figure 2, we see that fast contributions (i.e., those below median response time) are similarly distributed in both treatments. In contrast, slow decisions (i.e. those above median response time), depicted in the upper segments of Figure 2, exhibit very different patterns in the two treatments. ${ }^{24}$ Fast decision makers, in both treatments, choose contributions that are scattered over the whole range of possible choices. In particular, contributions that are dominated from a selfish as well as a social perspective are associated with fast response times in both treatments. Fast decision makers are more likely to contribute below the dominant strategy and above the group-payoff maximizing contribution of $\$ 9$. By contrast, looking at the upper segments of the two graphs, we see that slow decision makers are more likely to select a contribution at the equilibrium prediction. Slow decision makers also account for almost all of the few group-payoff maximizing contributions.

Table 3 summarizes the information contained in Figure 2. There we define mistakes as choices that are outside the core, i.e., contributions that simultaneously lower payoffs of both the individual and other group members. Contributions outside the core range from $\$ 0$ to $\$ 2$ in the Low treatment and from $\$ 0$ to $\$ 6$ in the High treatment. We see in both treatments that a large majority $(>70 \%)$ of such choices are made by fast decision makers. Hence, we reject the null hypothesis that slow and fast decision makers are equally likely to make mistakes (2-sided Fisher's exact test $\mathrm{p}<0.01$ in the pooled sample). By contrast, equilibrium contributions are more likely to be made by slow decision makers (2-sided Fisher's exact test $p<0.01$ in the pooled sample). Contributions of $\$ 10$, which at a very high cost increase the payoffs of others and thus are dominated from a group-payoff maximizing perspective are also associated with fast responses (2-sided Fisher's exact test $\mathrm{p}<0.01$ in the pooled sample). ${ }^{25}$

Table 3. Contributions by treatment, Part 1

\begin{tabular}{|c|c|c|c|c|c|c|}
\hline \multirow{3}{*}{ Choices } & \multicolumn{6}{|c|}{ Treatment } \\
\hline & \multicolumn{2}{|c|}{ Low NE } & \multicolumn{2}{|c|}{ High NE } & \multicolumn{2}{|c|}{ All } \\
\hline & $\mathrm{n}$ & (\% fast $)$ & $\mathrm{N}$ & (\% fast) & $\mathrm{n}$ & ( $\%$ fast $)$ \\
\hline Mistakes (outside the core) & 4 & $(75)$ & 29 & $(72)$ & 33 & $(72)$ \\
\hline Nash equilibrium & 28 & $(39)$ & 29 & $(21)$ & 57 & $(30)$ \\
\hline Above Nash \& below group payoff max. & 38 & $(53)$ & 10 & $(50)$ & 48 & $(52)$ \\
\hline Group payoff maximizing & 4 & $(25)$ & 4 & $(0)$ & 8 & $(13)$ \\
\hline Full provision (reducing group payoff) & 6 & $(100)$ & 8 & $(88)$ & 14 & (93) \\
\hline Midpoint of strategy space & 13 & $(46)$ & 12 & $(33)$ & 25 & $(56)$ \\
\hline All & 80 & $(51)$ & 80 & (49) & 160 & $(50)$ \\
\hline
\end{tabular}

\footnotetext{
${ }^{24}$ For fast decision makers, the distributions of contributions do not differ significantly by treatment (Wilcoxon Mann-Whitney rank-sum test yields $\mathrm{p}=0.232$, and Kolmogorov-Smirnov $\mathrm{p}=0.167$ ), whereas those for slow decision makers do ( $\mathrm{p}<0.01$ for both Wilcoxon Mann-Whitney rank-sum and Kolmogorov-Smirnov tests).

${ }^{25}$ We report pooled data statistics because the number of observations is very small for the Low treatment. The 2sided Fisher's exact test statistics for the Low and High treatment separately are for mistakes (Low: p=0.616; High: $\mathrm{p}<0.01$ ), equilibrium contributions (Low: $\mathrm{p}=0.160$; High: $\mathrm{p}<0.01$ ), and contributions of $\$ 10$ ( $\mathrm{p}<0.05$ in both treatments). The extent to which a $\$ 10$ contribution is a mistake is examined in a modified treatment where the core is interior to the strategy space and contributions of $\$ 10$ lower the payoffs of every group member (see section 4.5 ).
} 
Figure 3 presents the mean contributions made by fast and slow decision makers in each treatment. While there are no differences in the average contributions made by fast decision makers $($ Mean Low $=\$ 5.54$, Mean High $=\$ 6.08, \mathrm{p}=0.380)$, there are substantial differences in the average contributions made by slow decision makers (Mean Low $=\$ 4.56$, Mean High $=$ $\$ 7.05, \mathrm{p}<0.01) .{ }^{26}$ Consistent with the results presented in Table 2 we find in the Low treatment that slow decision makers contribute less than fast decision makers, but that the reverse holds true in the High treatment ( $p=0.072$ and 0.042 in each treatment respectively). We also note that in both treatments standard errors are smaller for slow decision makers. Tests for differences in the standard deviation of contributions reject the null hypothesis that the variance of the contributions is the same for fast and slow decision makers (Brown - Forsythe robust test $\mathrm{p}<0.05$ in both treatments).

Figure 3. Mean contribution by fast and slow decision makers, Part 1

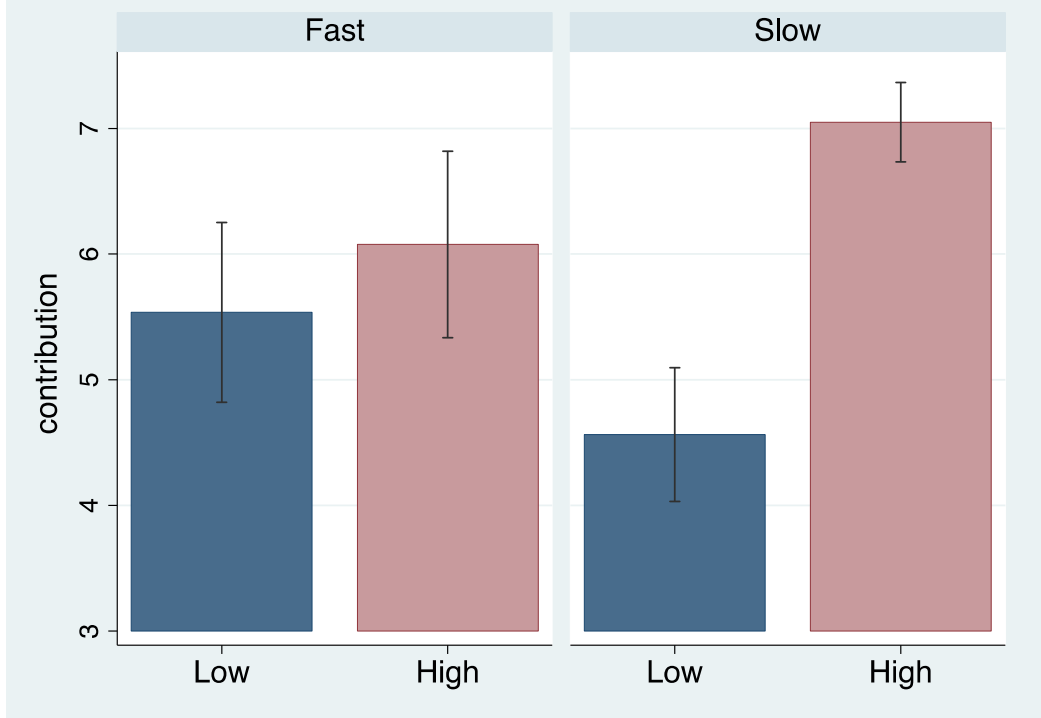

Note: Fast indicates that choices were made in less than the median response time ( 41.5 seconds), and slow indicates that choices were made in more than the median response time.

Are the results reported so far robust with respect to adding other explanatory variables? We examine whether age, gender, the number of tutorial questions answered correctly, training in economics, and experience with laboratory experiments affect response times and contributions and report the detailed results in Table A2 of the appendix. Importantly, the reversal of the

\footnotetext{
${ }^{26}$ The similarity in contributions for fast decision makers suggest that the reversal of correlation between the Low and High treatments cannot be explained by a model of drift-diffusion (DDM). Krajbich, Bartling, Hare, and Fehr (2014) examine how consistent with DDM changes in MPCR can reverse the correlation between generosity and response time. They have subjects make repeated choices with various MPCRs and show that contributions are positively correlated with response time when the MPCR equals 0.3 and 0.5 , but are negatively correlated when the MPCR equal 0.9. The authors argue that fast choices reflect strong preferences not intuitive responses and that DDM can explain the negative correlation between response time and giving documented in Rand et al. (2012).
} 
correlation between response times and contributions documented in Table 2 is robust to controlling for all of these variables as well as to excluding outlier observations. ${ }^{27}$

Our results from Part 1 show that the correlation between response times and contributions is sensitive to the strategic environment. While fast decision makers are not generally more generous than slow decision makers, they are more likely to select a contribution that simultaneously lowers individual and group payoffs, and their average contribution appears to be independent of the treatment. A greater error rate for fast decision makers likely attributes to the VCM finding that response times and contributions are negatively correlated. To further investigate the potential role of mistakes we next examine the choices participants make when the game is repeated in Part 2 of the experiment.

\subsection{Part 2: Contributions}

At the completion of Part 1 participants are informed that Part 2 will be a ten period version of Part 1. Behavior in Part 2 helps determine whether participants change their choices when given additional contribution options, and whether behavior converges over time.

Figure 4. Mean and median contribution by period and treatment

(Equilibrium contributions: Low $g^{L}=3$, High $g^{H}=7$ )

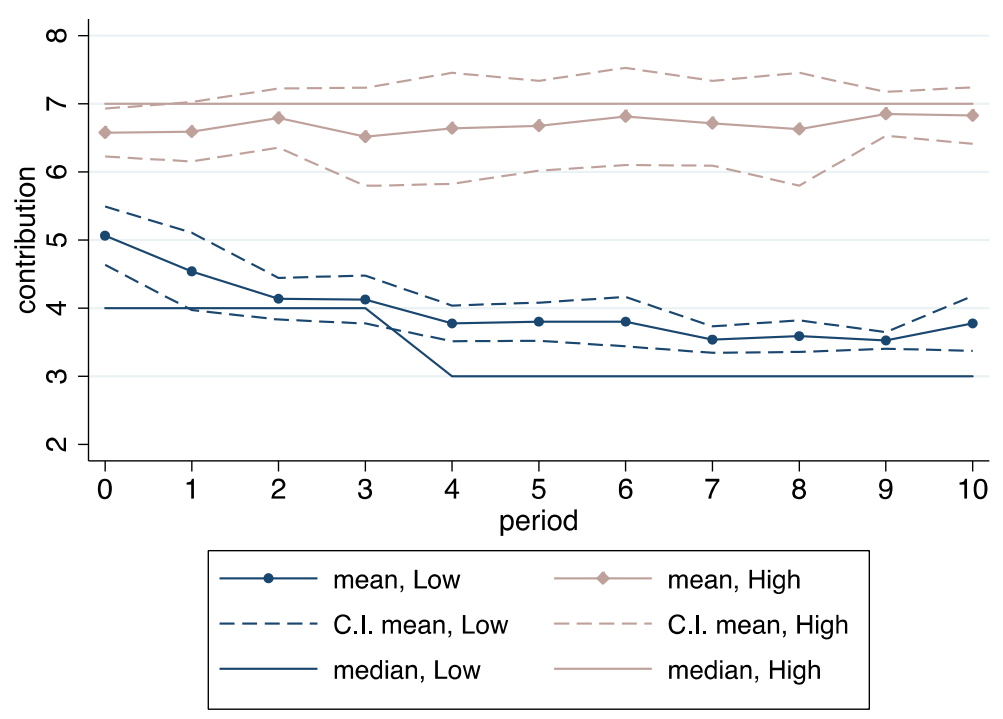

Note: $90 \%$ confidence interval of mean session contribution depicted.

Period 0 denotes Part 1.

Repeated experience with the environment increases the frequency of equilibrium play. Overall, the share of equilibrium contributions increases from one third in Part 1 to two thirds in period

27 Eliminating observations with response times in excess of 150 seconds does not alter the coefficients on response time reported in Table 2 (irrespective of whether or not the full set of additional controls is included in the regressions). Results of these regressions are available upon request. 
10 of Part $2 .^{28}$ Figure 4 shows the mean and median contributions by period and treatment, with period 0 reporting contributions in Part 1 . We see that average contributions converge to the equilibrium prediction from above in the Low treatment and from below in the High treatment. While convergence from above in the Low treatment can be justified by participants over time moving from an intuitively-generous response to a more calculated-selfish response, there is no such justification for the convergence from below in the High treatment. No selfish or altruistically inclined participant should contribute below the equilibrium in the High treatment. While on average undercontribution is eliminated in the High treatment, overcontribution persists in the Low treatment. By period 4, however, the median contribution of each of the two treatments equals the respective equilibrium predictions.

\subsection{Part 2: Response time and contributions}

The response time per period decreases dramatically when moving from Part 1 to Part 2 and continues to decrease over periods in Part 2. The median response time falls from 41.5 seconds in Part 1 to below 10 seconds by the third period of Part 2. Note however that the per period response time no longer can be seen as measuring the time it takes an individual to make a decision. Factors such as the period of play, received feedback, and overall experience likely influence the choice made in a particular period. As a result it is perhaps not surprising that the treatment differences in the correlation between response times and contributions no longer holds when looking at the within-period correlations in Part 2 of the experiment. ${ }^{29}$

The more important question is perhaps whether the classification of participants as slow and fast decision makers in Part 1 helps predict behavior in Part 2. If response time in Part 1 is reflective of preferences over payoffs then we would expect the Part-1 classification to influence behavior in Part 2. Figures 5 and 6 below demonstrate by treatment, response time, and contributions according to the Part 1 classification. Looking first at the Low treatment we see that initial differences between fast and slow decision makers are essentially eliminated by Part 2 . Differences between fast and slow decision makers also decrease with repetition in the High treatment; however, the gap remains and fast decision makers continue to exhibit lower response times and lower mean contributions. As seen in the right hand panel of Figure 6 median contributions do not differ by the initial classification, and behavior in both the Low and High treatments ultimately converges to the equilibrium predictions.

\footnotetext{
28 The share of equilibrium play increases from 35 to 69 percent in the Low treatment and from 36 to 79 percent in the High treatment when moving from Part 1 to period 10 of Part 2.

${ }^{29}$ The within-period correlation between response time and giving is positive in both treatments. Including individual random effects and clustering standard errors at the session level a regression of contributions in the Low treatment results in the following coefficients (and standard errors): a constant of 3.97 (0.194), a coefficient on response time of $0.020(0.007)$, and a coefficient on period of $-0.058(0.018)$. Results from the High treatment are instead a constant of $6.445(0.322)$, a coefficient on response time of $0.009(0.006)$, and a coefficient on period of $0.031(0.008)$. The reversal of the coefficients on period in the Low and High treatments confirm convergence from the middle. Pooling the data reveals that the coefficient on period differs by treatment, $\mathrm{p}<0.001$.
} 
Figure 5. Median response time by fast and slow decision makers in Part 1

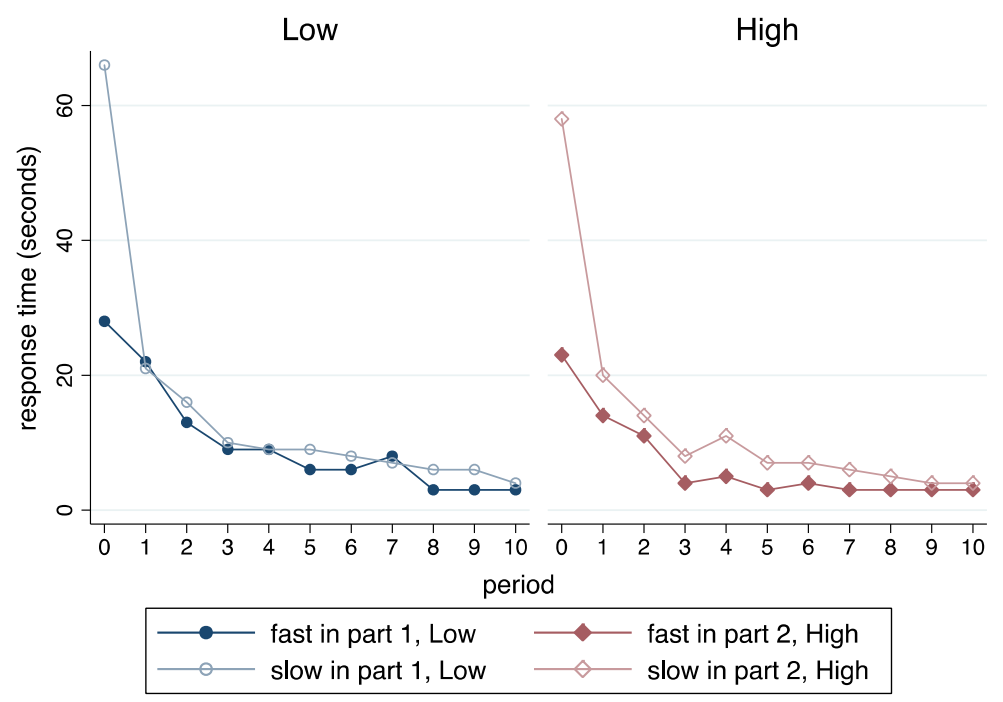

Figure 6. Mean and median contribution by fast and slow decision makers in Part 1
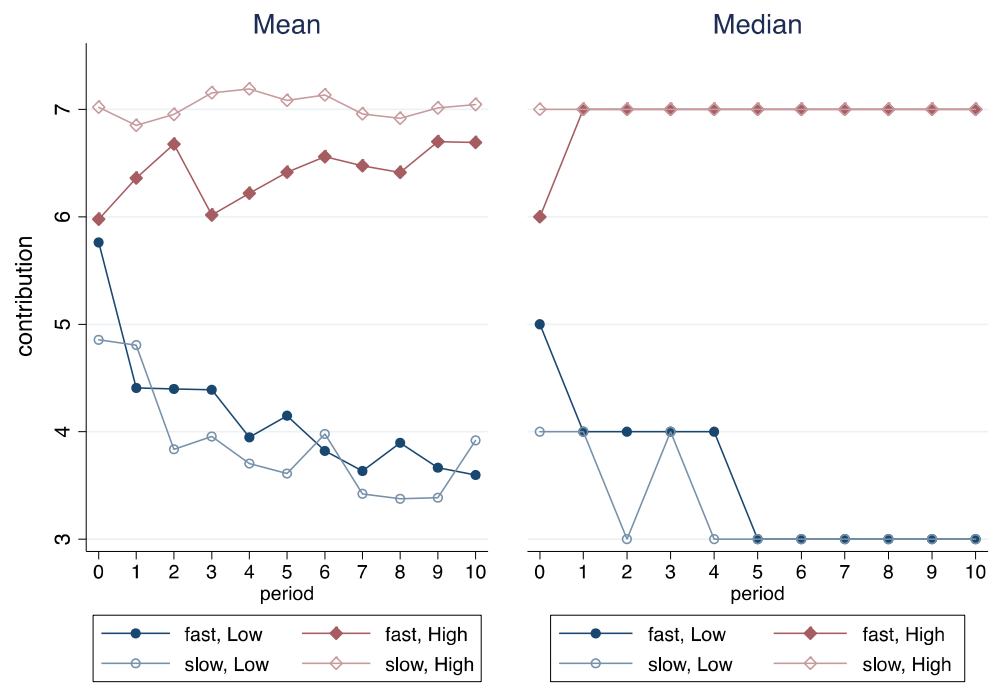

The random effects regressions presented in Table 4 confirm the insights from the left panel of Figure 6. For both the Low and High treatment we see in columns (1) and (2) that the Part-1 classification as a fast decision maker is statistically significant and does affect the individual's Part-2 contributions. Note however that contributions in the Low and High treatments converge from opposite directions. With repetition contributions decrease in the Low treatment, while they increase in the High treatment. It is difficult to reconcile these changes with the initial classification of fast and slow as being reflective of preferences, in particular when we account for contributions below the dominant strategy of $\$ 7$ in the High treatment simultaneously decreasing own and group payoff. 
The opposing directions of the convergence seen in Part 2 are consistent with our interpretation that differences in Part-1 contributions by fast- and slow decision makers result from a higher rate of mistakes for fast decision makers. Certainly, the observed differences are not supportive of the hypothesis that fast decision makers are more generous.

Table 4: OLS regression of contribution on response time in Part 2

\begin{tabular}{|c|c|c|c|}
\hline \multirow{2}{*}{$\begin{array}{l}\text { Dep. Var.: Contribution to group } \\
\text { account }\end{array}$} & \multicolumn{3}{|c|}{ Treatment } \\
\hline & $\begin{array}{c}\text { Low } \\
(1)\end{array}$ & $\begin{array}{l}\text { High } \\
(2) \\
\end{array}$ & $\begin{array}{l}\text { All } \\
(3)\end{array}$ \\
\hline \multirow[t]{2}{*}{ fast in part 1} & $0.232^{* *}$ & $-0.745^{* * *}$ & $0.232^{* *}$ \\
\hline & $(0.102)$ & $(0.283)$ & $(0.094)$ \\
\hline \multirow[t]{2}{*}{ Period } & $-0.088^{* * *}$ & $0.021 * * *$ & $-0.088^{* * *}$ \\
\hline & $(0.019)$ & $(0.007)$ & $(0.017)$ \\
\hline \multirow[t]{2}{*}{ High } & & & $2.723^{* * *}$ \\
\hline & & & $(0.175)$ \\
\hline \multirow[t]{2}{*}{ High $\mathrm{X}$ fast in part 1} & & & $-0.977 * * *$ \\
\hline & & & $(0.278)$ \\
\hline \multirow[t]{2}{*}{ High X period } & & & $0.109 * * *$ \\
\hline & & & $(0.019)$ \\
\hline \multirow[t]{2}{*}{ Constant } & $4.226^{* * *}$ & $6.949 * * *$ & $4.226^{* * * *}$ \\
\hline & $(0.156)$ & $(0.106)$ & $(0.144)$ \\
\hline \multirow[t]{2}{*}{ Total effect fast in part 1: High } & & & $-0.745^{* * *}$ \\
\hline & & & $(0.262)$ \\
\hline \multirow[t]{2}{*}{ Total effect period: High } & & & $0.021 * * *$ \\
\hline & & & $(0.007)$ \\
\hline $\mathrm{N}$ & 800 & 800 & 1600 \\
\hline
\end{tabular}

\subsection{Robustness checks}

Rather than finding evidence that fast decision makers hold different preferences over payoffs, our results indicate that fast decision makers in the one-shot Part 1 environment are more prone to mistakes. To further explore the role of mistakes we modify our initial experimental design and examine contributions in two additional sets of public good experiments. The first set of experiments allows us determine whether our results extend to the classic VCM environment, where the marginal private return from contributing is constant across contributions. With the second set of experiments we test whether in our initial design full provision can indeed be interpreted as a mistake.

We first report on results that extend the analysis to VCM-like environments. To characterize decisions as mistakes our initial experiments use piece-wise linear payoffs to place both the dominant strategy and the group's payoff maximizing contribution in the interior of the strategy 
space. While well suited for classifying mistakes, the associated payoff structure is perhaps more complex than in the VCM. It may thus be argued that the documented mistakes result from this greater complexity. Using a Low and High version of the classic VCM we ask if similar comparative statics arise when the private return from giving is held constant across contributions. Building on our initial design we examine contributions in both a Low- and a High-VCM treatment. The incentives of the Low-VCM are equal to those of Rand et al. (2012). Members of a four-person group can contribute none, parts, or all of an $\$ 8$ endowment to a group account, where every contributed dollar is doubled and split equally between group members. ${ }^{30}$ With a marginal per capita return (MPCR) of $\$ 0.50$, the equilibrium contribution is zero. For the High-VCM we secure an equilibrium of full provision by adding to the $\$ 0.50 \mathrm{MPCR}$ an individual contribution bonus of $\$ 0.60$ per dollar contributed. Only the individual contributing receives the contribution bonus. While keeping constant across treatments the marginal benefit to others from contributing, the individual contribution bonus moves the dominant strategy equilibrium from zero provision in the Low-VCM to full provision in the High-VCM treatment. ${ }^{31}$ Following past VCM procedures the payoffs are characterized without the use of a payoff table. Absent the payoff table and the associated tutorial, all procedures are as in our initial treatments.

We conducted four sessions of the VCM treatments, two sessions of the Low-VCM treatment and two sessions of the High-VCM treatment. 40 individuals participated in the Low-VCM and 36 participated in the High-VCM. The median decision time of 35.5 seconds in the pooled VCM is slightly shorter than that in the initial treatments and we use this median time to distinguish between fast and slow decision makers. Starting with the High-VCM we replicate the results from the initial High treatment. Average contributions by fast decision makers are much smaller than those by slow decision makers ( $\$ 2.86$ vs. $\$ 6.07, \mathrm{p}<0.01)$. Ignoring an outlier, qualitatively the results in Table 2 replicate and show that contributions in the High-VCM increase with response time. ${ }^{32}$ The Low-VCM however does not replicate the correlation between response times and contributions, and with average contributions by fast and slow decision makers of $\$ 3.41$ and $\$ 4.09$, respectively, there is no statistically significant difference between the two

\footnotetext{
30 To secure payoff ranges similar to that in our initial design we provide each participant with an $\$ 8$ endowment. This secures comparable maximum group payoffs across treatments. See the appendix for instructions and payoff descriptions. Payoff descriptions were provided on the screen used to make contribution decisions. Response time was measured from the moment the decision screen was shown.

${ }^{31}$ The payoff structure in the Low- and High-VCM treatments make it difficult to determine what drives choices. Deviations from the dominant strategy in the Low-VCM are in the core and may result from mistakes or concern for others. By contrast all deviations from the dominant strategy in the High-VCM are outside the core, and the dominant strategy simultaneously maximizes individual and group payoffs. While generosity and mistakes cannot be distinguished in the Low-VCM, generosity and individual payoff-maximizing behavior cannot be distinguished in the High-VCM.

32 One participant in the High-VCM had a response time of 277 seconds and contributed nothing, by comparison the second slowest response time was 103 seconds. Eliminating this outlier and regressing contributions on response time yields a coefficient (standard error) of $0.103(0.019)$. Similar results are obtained in a Tobit regression where the coefficient (standard error) on response time is 0.159 (0.037).
} 
$(p=0.467) .{ }^{33}$ While not replicating Rand et al.'s Low-VCM finding, our result is consistent with our earlier finding that slow decision makers more frequently contribute the equilibrium and group-payoff maximizing amount. As in our initial treatments we continue to see that the frequency of equilibrium play is higher for slow than fast decision makers. Fast decision makers account for 38 percent of equilibrium play in the Low-VCM and 22 percent in the High-VCM. ${ }^{34}$ Finally it continues to be the case that while we cannot distinguish by treatment the mean contributions by fast decision makers (Mean Low $=\$ 3.41$, Mean High $=\$ 2.86, p=0.53$ ), those by slow decision makers are easily distinguishable (Mean Low $=\$ 4.09$, Mean High $=\$ 6.07, p=0.03$ ). Our second modification of our initial design tests whether full provision can be seen as a mistake. In the initial treatments, in analyzing the results from Part 1 we found that contributions of $\$ 10$ were predominantly made by fast decision makers. Noting that the individual cost of contributing \$10 rather than \$9 is substantial and only results in a limited increase in earnings for others, implying a decrease in group payoff. These group payoff-reducing contributions may be seen as mistakes, but may also be justified for someone who values payoff-to-others much more than payoff-to-self. ${ }^{35}$ With a slight modification we can eliminate the second explanation. Specifically we modify the payoffs to secure that individuals, in increasing their contributions from $\$ 9$ to $\$ 10$, lower both their own payoffs and those of every other member of the group. That is, the marginal benefit of contributing $\$ 10$ is negative for both the individual and for each of the other group members. ${ }^{36}$ This change in payoffs places the core strictly in the interior of the strategy space. We conduct four sessions of these treatments, two with a Low-Interior treatment and two with a High-Interior treatment. With 40 participants in each treatment, a total of 80 individuals participated. All other parameters and experimental procedures were unchanged relative to our initial piece-wise linear design.

33 A regression of contributions on response time in the Low-VCM yields a coefficient (standard error) of 0.015 (0.024).Similar results are obtained in a Tobit regression where the coefficient (standard error) on response time is 0.019 (0.040).

${ }^{34}$ Part 2 of the VCM treatments shows convergence to equilibrium from above in the Low-VCM, but no convergence to equilibrium in the High-VCM. In the Low-VCM the frequency of equilibrium play increases from 20 percent in Part 1 to 70 percent in period 10 of Part 2, by contrast the frequency of equilibrium play in the HighVCM remains below 25 percent throughout Part 2, and average and median contributions never exceed \$5. We ran a second version of the High-VCM to determine whether behavior also failed to converge when the positive marginal return from giving was made even more salient. The first version of the High-VCM presented the bonus as an individualized 60 cent bonus for contributing, the second version (High-VCM2) noted in addition that the total return from contributing \$1 was $\$ 1.10$. Two sessions were conducted of High-VCM2 with a total of 36 participants. Behavior in High-VCM2 also failed to converge with the frequency of equilibrium play decreasing from 30 to 20 percent during Part 2. The lack of convergence in these High-VCM treatments may result from non-equilibrium play securing higher relative earnings in groups where some participants contribute less than the dominant strategy (e.g., in four person groups with contributions $(8,0,0,0)$ earnings are $(8.8,16.8,16.8,16.8))$. These differences in relative earnings may hinder convergence as non-equilibrium play is reinforced and because those contributing becoming increasingly frustrated by the unequal payoff distributions (see also Reuben and Riedl, 2009).

${ }^{35}$ In the initial treatments (with piece-wise linear payoff structures) the marginal cost of giving $\$ 10$ rather than $\$ 9$ is $\$ 3.25$ in the Low treatment and $\$ 1.25$ the High treatment. The marginal benefit to others from contributing is $\$ 0.75$, or $\$ 0.25$ per group member. Contributions of $\$ 10$ rather than $\$ 9$ thus decrease total group payoffs by $\$ 2.50$ and $\$ 0.50$ in the Low and High treatments, respectively.

${ }^{36}$ The payoff tables used in these Interior treatments are shown in online Appendix Table A3 and A4. $\delta$ is set to 2.25 and -0.25 in the Low- and High-Interior treatments, respectively, and $\sigma=-0.15$ in both treatments when $g_{i}>9$. 
Results from the Low-Interior and High-Interior treatments reveal that in comparison to the initial High and Low treatments the frequency of $\$ 10$ contributions does not decrease when full provision lowers the payoffs of all group members. 10 percent of participants contribute $\$ 10$ in the Low-Interior treatment and 15 percent contribute $\$ 10$ in the High-Interior treatment. ${ }^{37}$ As in the initial treatment $\$ 10$ contributions are primarily made by fast decision makers. Fast decisions account for 75 percent and 83 percent of the $\$ 10$ contributions in the Low-Interior and HighInterior treatments, respectively. ${ }^{38}$ Importantly the modification of the payoffs resulting from a $\$ 10$ contribution does not alter the comparative statics in comparison to the initial treatments.

The results from the two additional sets of treatments are consistent with the interpretation of our initial data. Fast decision makers are less sensitive to individual and social incentives and more prone to make mistakes. These characteristics make them appear more generous in some circumstances but less generous in others. Together it makes fast decisions inconsistent with an interpretation seeing them as reflective of preferences over payoffs to self and others. Rather than being evidence of intuitive generosity, the negative correlation between response time and giving in the linear public good game instead likely results from a positive correlation of fast decisions with mistakes.

\section{Conclusion}

Response time is increasingly used to draw inference on individual preferences. We argue that such inference is misleading when mistakes are correlated with response time. To demonstrate we revisit the finding that response time is negatively correlated with contributions in linear public good games. While this finding has been seen as evidence that individuals are intuitively generous, we argue that large fast contributions instead may result from individuals making mistakes.

Examining contributions in public good games with unique interior equilibria, we show that the correlation between response times and contributions reverses with the location of the equilibrium. The correlation is negative when the equilibrium is located below the midpoint of the strategy space, and it is positive when the equilibrium is located above the midpoint of the strategy space. Despite the fact that incentives change with the location of the equilibrium, we find that mean contributions for fast decision makers are independent of the location of the equilibrium. In our study we use piece-wise linear payoffs that allow us to identify mistakes as choices that lower both individual and group payoffs, and let us show that the frequency of mistakes decreases with response time. The pattern of contributions suggests that fast responses

\footnotetext{
${ }^{37}$ In the initial Low (High) treatment 8 (10) percent contribute $\$ 10$.

${ }^{38}$ With the smaller sample size some results are, however, not statistically significant. The correlation between response times and contributions in Part 1 is negative in the Interior-Low treatment and positive in the Interior-High treatment. Mean contributions are not distinguishable for fast decision makers (Mean Low-Interior $=\$ 6.22$, Mean High-Interior $=\$ 6.00, \mathrm{p}=0.599)$, but are distinguishable for slow decision makers $($ Mean Low-Interior $=\$ 5.00$, Mean High-Interior $=\$ 6.88, \mathrm{p}<0.01)$. Part 2 results show the same convergence documented in section 4.3 .
} 
rather than being reflective of an intuitively generous action result from fast decision makers quickly selecting contributions that lie, on average, in the middle of the strategy space. ${ }^{39}$

Our evidence that mistakes confound the inference on preferences from response time suggests that caution is warranted when considering other experimental manipulations that also interact with mistakes. For example, to determine whether giving is intuitive we may ask whether giving increases when participants have less time to make a decision. Note, however, that such a manipulation is also likely to increase the rate of error. Similarly, giving participants an option to revise an initial decision to determine whether fast decisions are impulsive will not only result in corrections for those who in the heat of the moment opted to contribute, but also cause those who made a mistake to correct their decision. Just as response time is correlated with error, experimental manipulations that influence error will make inference on preferences difficult.

The results of our paper extend beyond the study of response time and intuitive choices in a social dilemma setting. In particular, it suggests that independent of the environment caution is warranted when trying to draw inferences about preferences from response time. While we found fast decision makers to be insensitive to the payoffs associated with their choices, slow decision makers were instead very sensitive to changes in payoffs. If anything, our results suggest that the choices made by slow decision makers better reflect individual preferences over payoffs.

The concern for error raised here is likely to be greater when examining one-shot interactions. Response time may better reflect preferences in environments, such as those recently used to study drift diffusion, where individuals are presented with choices between familiar products and asked to repeatedly make decisions in comparable environments. The persistent differences between fast and slow decision makers seen in Part 2 of our study however suggests that researchers who wish to examine response time may nonetheless want to augment their designs to secure that mistakes, and changes in these, can be identified within the study.

Finally, our study suggests that theoretical models of decision making need to take into account not only the possibility of dual processes and response time but also how errors relate to response time. Only with such models at hand will empirical researchers be able to use response time for unbiased inference on individual preferences.

\footnotetext{
${ }^{39}$ Our study also offers an explanation for the mixed results on the correlation between response time and generosity across strategic settings. Error may play a smaller role in simple settings and a larger role in more complex ones. This may explain why in the simple dictator game a positive correlation has been documented between kindness and response time (Piovesan and Wengström, 2008; Fiedler, Glöckner, Nicklish and Dickhert, 2013), while a negative correlation has been found in the linear public good game (Rand et al. 2012, Lotito et al. 2013, Nielsen et al. 2014) and in the more complex ultimatum game (Brañas-Garza, Meloso, and Miller 2013; and Rubinstein 2007).
} 


\section{References}

Agranov, M., A. Caplin, and C. Tergiman, "Naïve Play and the Process of Choice in Guessing Games", Working paper (2013).

Andreoni, J. "Cooperation in public-goods experiments: kindness or confusion?" The American Economic Review (1995): 891-904.

Arad, A.and A. Rubinstein. "Multi-dimensional iterative reasoning in action: The case of the Colonel Blotto game." Journal of Economic Behavior \& Organization 84, no. 2 (2012): 571-585.

Ariely, D., G. Loewenstein, and D. Prelec. "“Coherent arbitrariness": Stable demand curves without stable preferences." The Quarterly Journal of Economics 118, no. 1 (2003): 73106.

Benhabib, J., and A. Bisin. "Modeling internal commitment mechanisms and self-control: A neuroeconomics approach to consumption-saving decisions." Games and Economic Behavior 52, no. 2 (2005): 460-492.

Bernheim, B. Douglas, and Antonio Rangel. "Addiction and cue-triggered decision processes." American Economic Review (2004): 1558-1590.

Bracha, A., M. Menietti, and L. Vesterlund. "Seeds to succeed?: Sequential giving to public projects." Journal of Public Economics 95, no. 5 (2011): 416-427.

Brañas-Garza P., D. Meloso, and L. Miller, "Interactive and Moral Reasoning: A Comparative Study of Response Times", Working paper (2013).

Camerer, C., G. Loewenstein, and D. Prelec. "Neuroeconomics: How neuroscience can inform economics." Journal of economic Literature (2005): 9-64.

Cappelen, A. W., U. H. Nielsen, B. Tungodden, J. Tyran, and E. Wengström. "Fairness is intuitive", Working paper (2014).

Cappelletti, D., W. Güth, and M. Ploner. "Being of two minds: Ultimatum offers under cognitive constraints." Journal of Economic Psychology 32, no. 6 (2011): 940-950.

Caplin, A., and D.J. Martin. "Defaults and attention: The drop out effect", Working paper (2013).

Caplin, A., \& Schotter, A. (Eds.). (2008). The foundations of positive and normative economics: a handbook. Oxford University Press.

Chabris, C.F., C.L. Morris, D. Taubinsky, D. Laibson, and J.P. Schuldt. "The Allocation of Time in Decision-Making." Journal of the European Economic Association 7, no. 2-3 (2009): 628-637.

Chaudhuri, A.. "Sustaining cooperation in laboratory public goods experiments: a selective survey of the literature." Experimental Economics 14, no. 1 (2011): 47-83.

Clithero, J.A., and A. Rangel. "Combining Response Times and Choice Data Using a Neuroeconomic Model of the Decision Process Improves Out-of-Sample Predictions," Working paper (2013).

Crawford, V. (2008). Look-ups as the windows of the strategic soul: Studying cognition via information search in game experiments. In A. Caplin and A. Schotter (Eds.), Perspectives on the Future of Economics: Positive and Normative Foundations, Oxford University Press.

DellaVigna, S., J. A. List, and U. Malmendier. "Testing for altruism and social pressure in charitable giving." The Quarterly Journal of Economics127, no. 1 (2012): 1-56.

Evans, J.S.B. "Dual-processing accounts of reasoning, judgment, and social cognition." Annu. Rev. Psychol. 59 (2008): 255-278. 
Fudenberg, D., and D. K. Levine. "A dual-self model of impulse control." The American Economic Review (2006): 1449-1476.

Fudenberg, D., and D. K. Levine. "Timing and Self-Control." Econometrica 80, no. 1 (2012): 142.

Fiedler, S., A. Glöckner, A. Nicklish, and S. Dickhert, "Social Value Orientation and information search in social dilemmas: An eye-tracking analysis", Organizational Behavior and Human Decision Processes 120 (2013) 272-284.

Fischbacher, U. "z-Tree: Zurich toolbox for ready-made economic experiments." Experimental economics 10, no. 2 (2007): 171-178.

Houser, D., and R. Kurzban. "Revisiting kindness and confusion in public goods experiments", The American Economic Review 92, no. 4 (2002): 1062-1069.

Ibanez, M., S. Czermak, and M. Sutter. "Searching for a better deal-On the influence of group decision making, time pressure and gender on search behavior." Journal of Economic Psychology 30, no. 1 (2009): 1-10.

Isaac, R. M., James M. W., and S. H. Thomas. "Divergent evidence on free riding: An experimental examination of possible explanations." Public choice 43: 2 (1984): 113-149.

Kahneman, D. "Maps of bounded rationality: Psychology for behavioral economics." The American economic review 93, no. 5 (2003): 1449-1475.

Kahneman, D., Thinking, fast and slow. Macmillan (2011).

Kessler, J. B. Meier, S. "Learning from (Failed) Replications: Cognitive Load Manipulations and Charitable Giving", Journal of Economic Behavior and Organization 102 (2014) 10-13.

Kinnunen, S. P. and S. Windmann, "Dual-processing altruism", Frontiers in Psychology (2013).

Knoch, D., A. Pascual-Leone, K. Meyer, V. Treyer, and E. Fehr. "Diminishing reciprocal fairness by disrupting the right prefrontal cortex."Science 314, no. 5800 (2006): 829-832.

Kocher, M., and M. Sutter, "Time is money - Time pressure, incentives, and the quality of decision making", Journal of Economic Behavior and Organization 61 (2006) 375-392.

Kocher, M.G., P. Martinsson, K.O. Myrseth and C. Wollbrant. "Strong, Bold, and Kind: SelfControl and Cooperation in Social Dilemmas", Working paper (2012).

Kocher, M. G., J. Pahlke, and S. T. Trautmann. "Tempus fugit: time pressure in risky decisions." Management Science 59, no. 10 (2013): 2380-2391.

Krajbich, I., C. Armel, and A. Rangel. "Visual fixations and the computation and comparison of value in simple choice." Nature neuroscience 13, no. 10 (2010): 1292-1298.

Krajbich, I., B. Bartling, T. Hare, and E. Fehr. "Confounding intuition with strength of preference", Working paper (2014).

Krajbich, I., Dingchao L., C. Camerer, and A. Rangel. "The attentional drift-diffusion model extends to simple purchasing decisions."Frontiers in psychology 3 (2012).

Krajbich, I., and A. Rangel. "Multialternative drift-diffusion model predicts the relationship between visual fixations and choice in value-based decisions." Proceedings of the National Academy of Sciences 108.33 (2011): 13852-13857.

Krajbich, I., B. Oud, and E. Fehr. "Benefits of Neuroeconomic Modeling: New Policy Interventions and Predictors of Preference." American Economic Review 104, no. 5 (2014): 501-06.

Ledyard, John O., "Public Goods: A Survey of Experimental Research”, in Roth, A. E., and J. H. Kagel, The handbook of experimental economics. Vol. 1. Princeton University Press (1995) 111-194.

Lotito, G., M. Migheli, and G. Ortona. "Is cooperation instinctive? Evidence from the response times in a public goods game." Journal of Bioeconomics 15, no. 2 (2013): 123-133.

Loewenstein, G., and T. O’Donoghue. "Animal Spirits: Affective and Deliberative Processes in Economic Behavior." (2004). 
Martinsson, P., Myrseth, K.O.R., and, Wollbrant, C., (2012). "Reconciling pro-social vs. selfish behavior: On the role of self-control." Judgment and Decision Making, 7: 304-315.

Milosavljevic, M., J. Malmaud, A. Huth, C. Koch, and A. Rangel. "The drift diffusion model can account for value-based choice response times under high and low time pressure." Judgment and Decision Making 5, no. 6 (2010): 437-449.

Nielsen, U. H., J. Tyran, and E. Wengström. "Second Thoughts on Free Riding", Economic Letters 122, no. 2 (2014): 136-139.

Piovesan M. \& E. Wengström, "Fast or fair? A study of response times", Economic Letters, 105 (2009) 193-196.

Rand, D. G., A. Peysakhovich, G. T. Kraft-Todd, G. E. Newman, O. Wurzbacher, M. A. Nowak, and J.D. Greene. "Social heuristics shape intuitive cooperation." Nature communications 5 (2014).

Rand, D. G., J. D. Greene, and M. A. Nowak, "Spontaneous giving and calculated greed", Nature, 489 (2012) 427-430.

Rand, D. G., J. D. Greene, and M. A. Nowak, "Rand et al. reply" Nature 498, no. 7452 (2013): E2-E3.

Reuben, E. and A.Riedl, "Public Goods Provision and Sanctioning in Privileged Groups," The Journal of Conflict Resolution, 53, 1, (2009): 72-93.

Reutskaja, E., R. Nagel, C. F. Camerer, and A. Rangel. "Search dynamics in consumer choice under time pressure: An eye-tracking study." The American Economic Review 101, no. 2 (2011): 900-926.

Ruff, C. C., G. Ugazio, and E. Fehr. "Changing Social Norm Compliance with Noninvasive Brain Stimulation." Science 342, no. 6157 (2013): 482-484.

Rubinstein, A., "Instinctive and cognitive reasoning: a study of response times", The Economic Journal, 117 (2007) 1243-1259.

Rustichini, A. (2008). Dominance and competition. Journal of the European Economic Association, 6(2-3), 647-656.

Sanfey, A.G., J.K. Rilling, J.A. Aronson, L.E. Nystrom, and J.D. Cohen. "The neural basis of economic decision-making in the ultimatum game." Science 300, no. 5626 (2003): 17551758 .

Schotter, A., and I. Trevino. "Is response time predictive of choice? An experimental study of threshold strategies", Working paper (2012).

Shefrin, H. M., and R. H. Thaler. "The behavioral life-cycle hypothesis." Economic inquiry 26, no. 4 (1988): 609-643.

Smith, K., \& Dickhaut, J. Economics and emotion: Institutions matter. Games and Economic Behavior, 52(2), 316-335. (2005).

Strang, S., J. Gross, T. Schuhmann, A. Riedl, B. Weber, A. Sack. "Be Nice if You Have to - The Neurobiological Roots of Strategic Fairness." mimeo, Maastricht University. (2014).

Sutter, M., Kocher, M. and S. Strauß, "Bargaining under time pressure in an experimental ultimatum game", Economic Letters 81 (2003) 341-347.

Tinghög, G., D. Andersson, C. Bonn, H. Böttiger, C. Josephson, G. Lundgren, D. Västfjäll, M. Kirchler, and M. Johannesson. "Intuition and cooperation reconsidered." Nature 498, no. 7452 (2013): E1-E2.

Vesterlund, L., "Public Goods: Using experimental methods to understand how and why we give to charity" prepared for Roth, A. E., and J. H. Kagel, The handbook of experimental economics. Vol. 2. Forthcoming Princeton University Press. This version (2012).

Wilcox, N., "Lottery Choice: Incentives, Complexity, and Decision Time", The Economic Journal 103:241 (1993) 1397-1417. 


\section{Appendix (for publication)}

Table A1. Tobit regression of contribution, Part 1

\begin{tabular}{|c|c|c|c|}
\hline \multirow{3}{*}{ Dep. Var.: Contribution to group account } & \multicolumn{3}{|c|}{ Treatments } \\
\hline & Low & High & All \\
\hline & $(1)$ & $(2)$ & $(3)$ \\
\hline \multirow[t]{2}{*}{ Response time } & $-0.021 * *$ & $0.015^{* *}$ & $-0.021 * * *$ \\
\hline & $(0.008)$ & $(0.007)$ & $(0.008)$ \\
\hline \multirow[t]{2}{*}{ High } & & & -0.199 \\
\hline & & & $(0.650)$ \\
\hline \multirow[t]{2}{*}{ High $\mathrm{x}$ response time } & & & $0.035^{* * *}$ \\
\hline & & & $(0.011)$ \\
\hline \multirow[t]{2}{*}{ Constant } & $6.190 * * *$ & $5.970 * * *$ & $6.180^{* * *}$ \\
\hline & $(0.501)$ & $(0.418)$ & $(0.481)$ \\
\hline \multirow[t]{2}{*}{ Total effect response time: High } & & & $0.015^{* *}$ \\
\hline & & & $(0.007)$ \\
\hline $\mathrm{N}$ & 80 & 80 & 160 \\
\hline
\end{tabular}


Table A2. OLS regression of response time and contributions, Part 1

\begin{tabular}{|c|c|c|c|c|c|c|}
\hline \multirow{2}{*}{ Dependent Variable: } & \multicolumn{3}{|c|}{ Response time (seconds) } & \multicolumn{3}{|c|}{ Contribution to group account } \\
\hline & Low & High & All & Low & High & All \\
\hline \multirow[t]{2}{*}{ Response time } & & & & $-0.018^{* *}$ & $0.011 *$ & $-0.018^{* *}$ \\
\hline & & & & $(0.008)$ & $(0.007)$ & $(0.008)$ \\
\hline \multirow[t]{2}{*}{$\%$ tutorial correct } & 22.121 & 30.526 & 22.121 & -0.756 & $3.504^{* * *}$ & -0.756 \\
\hline & $(22.471)$ & $(21.749)$ & $(22.666)$ & $(1.607)$ & $(1.283)$ & $(1.479)$ \\
\hline \multirow[t]{2}{*}{ Experiments } & -0.824 & -0.948 & -0.824 & -0.021 & 0.003 & -0.021 \\
\hline & $(0.531)$ & $(0.648)$ & $(0.536)$ & $(0.038)$ & $(0.038)$ & $(0.035)$ \\
\hline \multirow[t]{2}{*}{ Econ courses } & 1.175 & $5.763^{* * *}$ & 1.175 & -0.105 & 0.038 & -0.105 \\
\hline & $(1.375)$ & $(1.937)$ & $(1.387)$ & $(0.098)$ & $(0.119)$ & $(0.090)$ \\
\hline \multirow[t]{2}{*}{ Age } & 2.353 & 2.094 & 2.353 & 0.091 & 0.256 & 0.091 \\
\hline & $(3.085)$ & $(3.272)$ & $(3.112)$ & $(0.220)$ & $(0.191)$ & $(0.203)$ \\
\hline \multirow[t]{2}{*}{ Female } & $-13.854 *$ & 5.358 & $-13.854 *$ & 0.034 & 0.423 & 0.034 \\
\hline & $(7.672)$ & $(7.916)$ & $(7.738)$ & $(0.557)$ & $(0.462)$ & $(0.513)$ \\
\hline \multirow[t]{2}{*}{ High } & & & -25.062 & & & -7.571 \\
\hline & & & $(89.289)$ & & & $(5.793)$ \\
\hline \multirow[t]{2}{*}{ High $\mathrm{X}$ response time } & & & & & & $0.029 * * *$ \\
\hline & & & & & & $(0.011)$ \\
\hline \multirow[t]{2}{*}{ High $\mathrm{X} \%$ tutorial correct } & & & 8.404 & & & $4.260^{* *}$ \\
\hline & & & $(31.286)$ & & & $(2.048)$ \\
\hline \multirow[t]{2}{*}{ High X experiments } & & & -0.123 & & & 0.024 \\
\hline & & & $(0.836)$ & & & $(0.055)$ \\
\hline \multirow[t]{2}{*}{ High $\mathrm{X}$ econ courses } & & & $4.588^{*}$ & & & 0.143 \\
\hline & & & $(2.369)$ & & & $(0.160)$ \\
\hline \multirow[t]{2}{*}{ High $\mathrm{X}$ age } & & & -0.259 & & & 0.165 \\
\hline & & & $(4.495)$ & & & $(0.292)$ \\
\hline \multirow[t]{2}{*}{ High X female } & & & $19.212^{*}$ & & & 0.389 \\
\hline & & & $(11.022)$ & & & $(0.724)$ \\
\hline \multirow[t]{2}{*}{ Constant } & -2.218 & -27.280 & -2.218 & 5.234 & -2.337 & 5.234 \\
\hline & $(63.195)$ & $(63.058)$ & $(63.744)$ & $(4.490)$ & $(3.676)$ & $(4.133)$ \\
\hline \multirow[t]{2}{*}{ Total effect response time: High } & & & & & & 0.011 \\
\hline & & & & & & $(0.007)$ \\
\hline \multirow[t]{2}{*}{ Total effect $\%$ tutorial correct: High } & & & 30.526 & & & $3.504^{* *}$ \\
\hline & & & $(21.565)$ & & & $(1.417)$ \\
\hline \multirow[t]{2}{*}{ Total effect experiments: High } & & & -0.948 & & & 0.003 \\
\hline & & & $(0.642)$ & & & $(0.042)$ \\
\hline \multirow[t]{2}{*}{ Total effect econ courses: High } & & & $5.763^{* * *}$ & & & 0.038 \\
\hline & & & $(1.921)$ & & & $(0.132)$ \\
\hline \multirow[t]{2}{*}{ Total effect age: High } & & & 2.094 & & & 0.256 \\
\hline & & & $(3.244)$ & & & $(0.211)$ \\
\hline \multirow[t]{2}{*}{ Total effect female: High } & & & 5.358 & & & 0.423 \\
\hline & & & $(7.849)$ & & & $(0.510)$ \\
\hline $\mathrm{N}$ & 80 & 80 & 160 & 80 & 80 & 160 \\
\hline
\end{tabular}




\section{Online Appendix (not for publication)}

\section{Instructions}

[ Piece-wise linear payoff structure ]

This is an experiment on decision making. The earnings you receive today will depend on the decisions made by you and by other participants in this room. Please do not talk or communicate with others in any way. If you have a question please raise your hand and an experimenter will come to where you are sitting to answer you in private.

\section{Earnings}

There will be two parts of the experiment. Only one of the two parts will count for payment. Once part 1 and 2 are completed we will flip a coin to determine which part counts for payment. Your earnings in the experiment will be the sum of a $\$ 6$ payment for showing up on time and your earnings from either part 1 or part 2 . We will first explain how earnings are determined in part 1. Once part 1 is completed we will explain how earnings in part 2 are determined. Decisions in part 1 only affect possible earnings in part 1, and decisions in part 2 only affect possible earnings in part 2. Your total earnings will be paid to you in cash and in private at the end of the experiment.

\section{Part 1}

In part 1 you will be matched in groups of four. That is the computer will randomly match you with three other participants.

You will each have to make one decision, and earnings will depend on the decision made by you and the decisions made by other members of your group. Neither during nor after the experiment will you get to know who the other members of your group are or what decisions they make. Likewise, no one in your group will know who you are and what decision you make.

You and each of the other group members will be given $\$ 10$ and asked to make an investment decision. You may select to invest any dollar amount between $\$ 0$ and $\$ 10$ in a group account. Investments in the group account affect both your earnings and those of the other members of the group. That is, individual earnings depend on the individual investment in the group account and the investment by the other group members.

\section{Decision Screen}

Your investment decision will be made using a decision screen. You make a decision by entering the number of dollars you wish to invest in the group account in the area labeled: Dollars to invest in group account. Once you have made your investment decision, please click the red 
Finalize Decision button. You will not be able to modify your decision once your choice is finalized.

A decision screen is shown below. The actual decision screen will include a payoff table with the earnings that result from the investments made by you and the three other group members. We will use the screenshot below to demonstrate how to read the table. The first column shows all possible investments by you. The first row shows all possible average investments by the other group members. If the average investment by the other group members is say $\$ 2$, then it may result from each investing $\$ 2$, or from one member investing $\$ 0$, another investing $\$ 2$, and a third investing $\$ 4$.

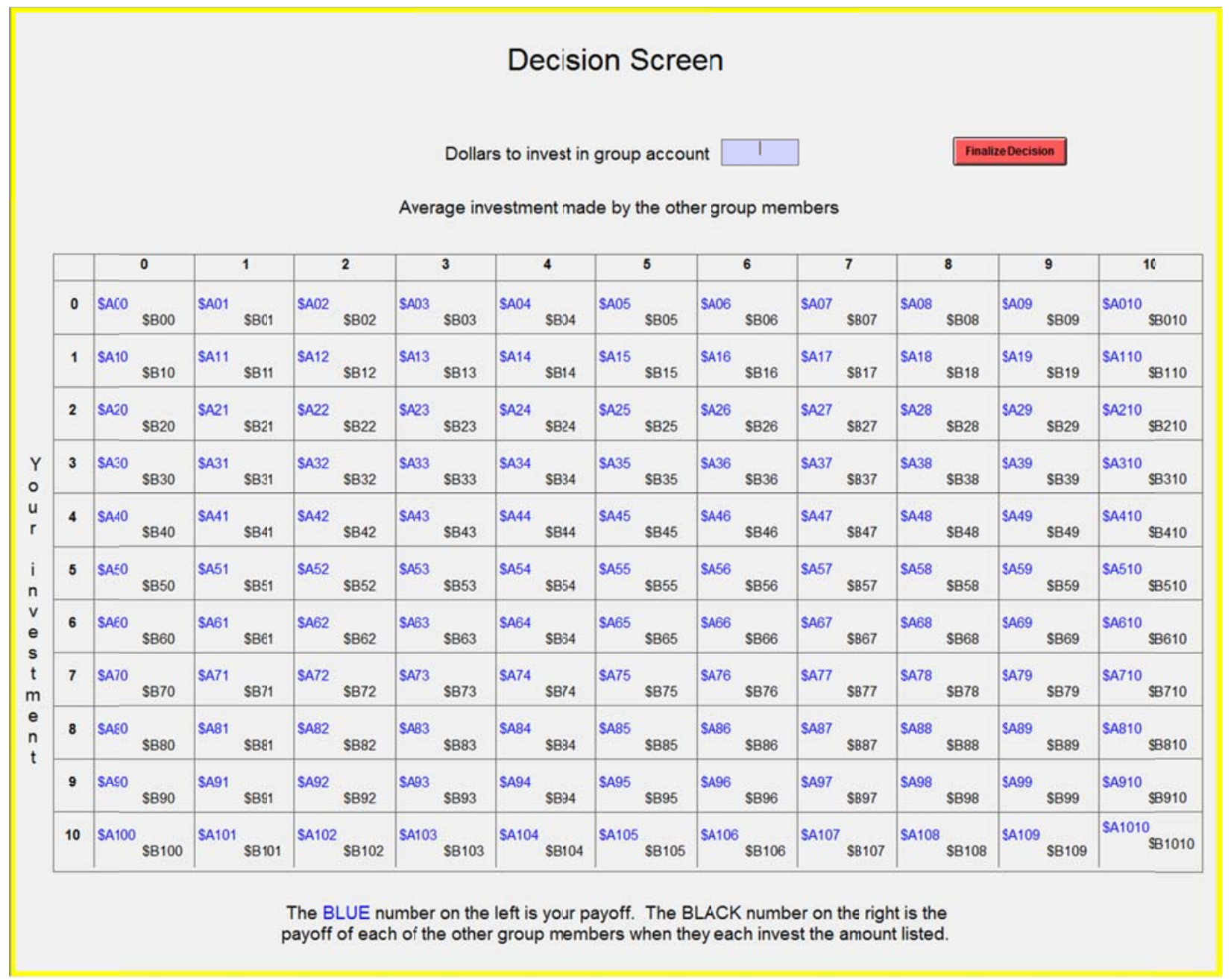

Each cell reports the payoff you and the other group members receive given your investment and the average investment by the other group members. Your payoff will be depicted in blue and located in the upper left corner of each cell. The average payoff of the other group members will be depicted in black and located in the bottom right corner of each cell. To determine the payoffs from a specific combination of investments you look at the cell where the row of your investment crosses the column of the average investment by the other group members. In this cell you will see your payoff on the left (in blue) and the average payoff of the other group 
members on the right (in black). The average payoff for the other group members refers to the payoff they each get when they invest the same amount in the group account.

Consider an example where you invest $\$ 1$ and the average investment by the other group members is $\$ 4$. Your earnings from this investment decision will be $\$ A 14$, where the first number refers to your $\$ 1$ investment and the second to the $\$ 4$ average investment by the other group members. Similarly the earnings of each of the three other group members will be \$B14. If you were to increase your investment to $\$ 2$ you move down one row to see that your earnings would become \$A24 and the average earnings of the other group members would become \$B24. Likewise if the average investment of the other group members increased by $\$ 1$, such that you invest $\$ 2$ and the other group members on average invest $\$ 5$, you move over one column to see that your earnings would become $\$ A 25$ and the average payoff to the other group members would be \$B25. Before we begin we will give you a tutorial on how to read the payoff table.

\section{Results Screen}

After everyone has made an investment decision you will see a results screen. The results screen will indicate the investments made by you and the other group members and will summarize the earnings you and the other group members receive if part 1 counts for payment. The average earnings for the other group members reported in the payoff table refer to the earnings that result when the three other group members make the same investment decision. In the event that they do not invest the same amount their actual average earnings may differ slightly from that reported in the table. Your own payoff from the listed investment combination will be precisely that listed in the payoff table.

\section{Instructions Part 2}

Part 2 is very similar to part 1 . The only difference is that you now must make investment decisions over a sequence of ten rounds. At the beginning of each round you will be randomly matched with three other people to form a new group of four. You will never be matched with the same three people twice in a row. It is also unlikely that you will meet the same set of three other group members twice. You will not get to know who the other members of your group are nor will you be informed of their past investment. Likewise, no one will know who you are and what investments you made in the past.

Just as for part 1 you will be presented with a decision screen which reports the earnings that you and the other group members get from the different investments. The decision screen will be the same in each round. That is, the earnings are the same for each of the ten rounds and are identical to those seen in part 1. 
After each round is complete you will be shown a result screen which reports the investments made by you and the other group members in that round, as well as the earnings you and the other group members made in that round.

If part 2 is selected for payment we will randomly select a number between one and ten. The earnings for the corresponding round will be paid to the participants along with the $\$ 6$ show up fee. The part that counts for payment will be determined by the flip of a coin. The round that counts in part 2 will be determined by having a participant draw a number between 1 and 10 . 
Table A1. Payoff table Low treatment

Average investment made by the other group members

\begin{tabular}{|c|c|c|c|c|c|c|c|c|c|c|c|}
\hline & 0 & 1 & 2 & 3 & 4 & 5 & 6 & 7 & 8 & 9 & 10 \\
\hline \multirow{2}{*}{0} & 10.00 & 10.75 & 11.50 & 12.25 & 13.00 & 13.75 & 14.50 & 15.25 & 16.00 & 16.75 & 17.50 \\
\hline & 10.00 & 11.95 & 13.90 & 15.85 & 16.10 & 16.35 & 16.60 & 16.85 & 16.85 & 16.85 & 14.10 \\
\hline \multirow{2}{*}{1} & 11.45 & 12.20 & 12.95 & 13.70 & 14.45 & 15.20 & 15.95 & 16.70 & 17.45 & 18.20 & 18.95 \\
\hline & 10.25 & 12.20 & 14.15 & \begin{tabular}{|r|}
16.10 \\
\end{tabular} & 16.35 & \begin{tabular}{|r|}
16.60 \\
\end{tabular} & \begin{tabular}{|r|}
16.85 \\
\end{tabular} & $\begin{array}{r}17.10 \\
\end{array}$ & 17.10 & 17.10 & 14.35 \\
\hline \multirow{2}{*}{2} & 12.90 & 13.65 & 14.40 & 15.15 & 15.90 & 16.65 & 17.40 & 18.15 & 18.90 & 19.65 & 20.40 \\
\hline & 10.50 & 12.45 & 14.40 & 16.35 & 16.60 & 16.85 & $\begin{array}{r}17.10 \\
\end{array}$ & 17.35 & 17.35 & 17.35 & 14.60 \\
\hline \multirow{2}{*}{3} & 14.35 & 15.10 & 15.85 & 16.60 & 17.35 & \begin{tabular}{|l|}
18.10 \\
\end{tabular} & \begin{tabular}{|l|}
18.85 \\
\end{tabular} & 19.60 & 20.35 & 21.10 & 21.85 \\
\hline & 10.75 & \begin{tabular}{|r|}
12.70 \\
\end{tabular} & 14.65 & \begin{tabular}{|r|}
16.60 \\
\end{tabular} & 16.85 & \begin{tabular}{|r|}
17.10 \\
\end{tabular} & \begin{tabular}{|r|}
17.35 \\
\end{tabular} & \begin{tabular}{|r|}
17.60 \\
\end{tabular} & 17.60 & 17.60 & 14.85 \\
\hline \multirow{2}{*}{4} & 14.10 & 14.85 & \begin{tabular}{|l|l}
15.60 \\
\end{tabular} & 16.35 & 17.10 & \begin{tabular}{|l|l}
17.85 \\
\end{tabular} & \begin{tabular}{|l|}
18.60 \\
\end{tabular} & 19.35 & 20.10 & 20.85 & 21.60 \\
\hline & 11.00 & \begin{tabular}{|r|}
12.95 \\
\end{tabular} & 14.90 & \begin{tabular}{|l|}
16.85 \\
\end{tabular} & 17.10 & 17.35 & \begin{tabular}{|r|}
17.60 \\
\end{tabular} & \begin{tabular}{|l|}
17.85 \\
\end{tabular} & 17.85 & 17.85 & 15.10 \\
\hline \multirow{2}{*}{5} & 13.85 & 14.60 & \begin{tabular}{|l|l|}
15.35 \\
\end{tabular} & \begin{tabular}{|l|}
16.10 \\
\end{tabular} & 16.85 & 17.60 & \begin{tabular}{|l|l|}
18.35 \\
\end{tabular} & 19.10 & \begin{tabular}{l|l}
19.85 \\
\end{tabular} & 20.60 & 21.35 \\
\hline & 11.25 & \begin{tabular}{|r|}
13.20 \\
\end{tabular} & 15.15 & 17.10 & $\begin{array}{r}17.35 \\
\end{array}$ & \begin{tabular}{|r|}
17.60 \\
\end{tabular} & \begin{tabular}{|r|}
17.85 \\
\end{tabular} & 18.10 & 18.10 & 18.10 & 15.35 \\
\hline \multirow{2}{*}{6} & 13.60 & 14.35 & 15.10 & 15.85 & 16.60 & 17.35 & 18.10 & 18.85 & 19.60 & 20.35 & 21.10 \\
\hline & 11.50 & \begin{tabular}{|r|}
13.45 \\
\end{tabular} & 15.40 & \begin{tabular}{|r|}
17.35 \\
\end{tabular} & \begin{tabular}{|r|}
17.60 \\
\end{tabular} & \begin{tabular}{|r|}
17.85 \\
\end{tabular} & 18.10 & 18.35 & 18.35 & 18.35 & 15.60 \\
\hline \multirow{2}{*}{7} & 13.35 & 14.10 & 14.85 & 15.60 & 16.35 & 17.10 & 17.85 & 18.60 & 19.35 & 20.10 & 20.85 \\
\hline & 11.75 & \begin{tabular}{|r|}
13.70 \\
\end{tabular} & 15.65 & 17.60 & \begin{tabular}{|r|}
17.85 \\
\end{tabular} & \begin{tabular}{|r|}
18.10 \\
\end{tabular} & \begin{tabular}{|r|}
18.35 \\
\end{tabular} & 18.60 & 18.60 & 18.60 & 15.85 \\
\hline \multirow{2}{*}{8} & 12.85 & 13.60 & 14.35 & 15.10 & 15.85 & 16.60 & 17.35 & 18.10 & 18.85 & 19.60 & 20.35 \\
\hline & 12.00 & 13.95 & 15.90 & \begin{tabular}{|r|}
17.85 \\
\end{tabular} & \begin{tabular}{|r|}
18.10 \\
\end{tabular} & \begin{tabular}{|r|}
18.35 \\
\end{tabular} & \begin{tabular}{|r|}
18.60 \\
\end{tabular} & 18.85 & 18.85 & 18.85 & 16.10 \\
\hline \multirow{2}{*}{9} & 12.35 & \begin{tabular}{|l|l}
13.10 \\
\end{tabular} & 13.85 & \begin{tabular}{|l|}
14.60 \\
\end{tabular} & \begin{tabular}{|l|l}
15.35 \\
\end{tabular} & \begin{tabular}{|l|}
16.10 \\
\end{tabular} & \begin{tabular}{|l|}
16.85 \\
\end{tabular} & 17.60 & \begin{tabular}{|l|l}
18.35 \\
\end{tabular} & \begin{tabular}{|l|l}
19.10 \\
\end{tabular} & 19.85 \\
\hline & 12.25 & 14.20 & 16.15 & 18.10 & 18.35 & $\begin{array}{r}18.60 \\
\end{array}$ & 18.85 & 19.10 & 19.10 & 19.10 & 16.35 \\
\hline \multirow{2}{*}{10} & \begin{tabular}{l|l}
9.10 \\
\end{tabular} & 9.85 & 10.60 & \begin{tabular}{|l|}
11.35 \\
\end{tabular} & 12.10 & 12.85 & \begin{tabular}{|l|}
13.60 \\
\end{tabular} & 14.35 & \begin{tabular}{|l|l}
15.10 \\
\end{tabular} & \begin{tabular}{|l|l}
15.85 \\
\end{tabular} & 16.60 \\
\hline & 12.50 & 14.45 & $\begin{array}{r}16.40 \\
\end{array}$ & $\begin{array}{r}18.35 \\
\end{array}$ & $\begin{array}{r}18.60 \\
\end{array}$ & $\begin{array}{r}18.85 \\
\end{array}$ & $\begin{array}{r}19.10 \\
\end{array}$ & 19.35 & 19.35 & 19.35 & 16.60 \\
\hline
\end{tabular}

The BLUE number on the left is your payoff. The BLACK number on the right is the payoff of each of the other group members when they each invest the amount listed. 
Table A2. Payoff table High treatment

Average investment made by the other group members

\begin{tabular}{|c|c|c|c|c|c|c|c|c|c|c|c|}
\hline & 0 & 1 & 2 & 3 & 4 & 5 & 6 & 1 & 0 & 9 & 10 \\
\hline \multirow{2}{*}{0} & 10.00 & 10.75 & 11.50 & 12.25 & 3.00 & 13.75 & 14.50 & 15.25 & 16.00 & 16.75 & 17.50 \\
\hline & 10.00 & 10.62 & 11.23 & 11.85 & 12.60 & 13.35 & 14.10 & & & & \\
\hline \multirow{2}{*}{1} & 0.12 & 10.87 & 11.62 & 12.37 & 13.12 & 13.87 & 14.62 & 15.37 & 16.12 & 16.87 & 17.62 \\
\hline & 10.25 & 10.87 & 11.48 & 12.10 & 12.85 & $\begin{array}{r}13.60 \\
\end{array}$ & $\begin{array}{r}14.35 \\
\end{array}$ & 15.10 & 15.10 & $\begin{array}{r}15.10 \\
\end{array}$ & 14 \\
\hline \multirow{2}{*}{2} & 10.23 & 10.98 & 11.73 & 12.48 & 13.23 & 13.98 & 14.73 & 15.48 & 16.23 & 16.98 & 17.73 \\
\hline & 10.50 & 11.12 & 11.73 & 12.35 & 13.10 & 13.85 & 14.60 & 15.35 & 15.35 & 15.35 & 14.6 \\
\hline \multirow{2}{*}{3} & 10.35 & 11.10 & 11.85 & 12.60 & 13.35 & 14.10 & 14.85 & 15.60 & 16.35 & 17.10 & 17.85 \\
\hline & 10.75 & \begin{tabular}{|l|}
11.37 \\
\end{tabular} & 11.98 & 12.60 & 13.35 & \begin{tabular}{|r|}
14.10 \\
\end{tabular} & 14.85 & 15.60 & 15.60 & \begin{tabular}{|r|}
15.60 \\
\end{tabular} & 14.8 \\
\hline \multirow{2}{*}{4} & 10.60 & 11.35 & 12.10 & 12.85 & 13.60 & \begin{tabular}{|l|}
14.35 \\
\end{tabular} & \begin{tabular}{|l|}
15.10 \\
\end{tabular} & 15.85 & 16.60 & \begin{tabular}{|l|}
17.35 \\
\end{tabular} & 18.10 \\
\hline & 11.00 & 11.62 & 12.23 & 12.85 & 13.60 & \begin{tabular}{|r|}
14.35 \\
\end{tabular} & \begin{tabular}{|r|}
15.10 \\
\end{tabular} & 15.85 & 15.85 & \begin{tabular}{|r|}
15.85 \\
\end{tabular} & \\
\hline \multirow{2}{*}{5} & 10.85 & 11.60 & 12.35 & 13.10 & 13.85 & \begin{tabular}{|l|}
14.60 \\
\end{tabular} & 15.35 & 16.10 & 16.85 & 17.60 & 18.35 \\
\hline & 11.25 & 11.87 & \begin{tabular}{|r|}
12.48 \\
\end{tabular} & \begin{tabular}{|r|}
13.10 \\
\end{tabular} & 13.85 & \begin{tabular}{|r|}
14.60 \\
\end{tabular} & \begin{tabular}{|r|}
15.35 \\
\end{tabular} & \begin{tabular}{|r|}
16.10 \\
\end{tabular} & \begin{tabular}{|l|}
16.10 \\
\end{tabular} & \begin{tabular}{|r|}
16.10 \\
\end{tabular} & 15.3 \\
\hline \multirow{2}{*}{6} & 11.10 & 11.85 & 12.60 & 13.35 & 14.10 & \begin{tabular}{|l|l}
14.85 \\
\end{tabular} & \begin{tabular}{|l|}
15.60 \\
\end{tabular} & 16.35 & 17.10 & \begin{tabular}{|l|l}
17.85 \\
\end{tabular} & 18.60 \\
\hline & 11.50 & $\begin{array}{r}12.12 \\
\end{array}$ & 12.73 & \begin{tabular}{|r|}
13.35 \\
\end{tabular} & 14.10 & $\begin{array}{r}14.85 \\
\end{array}$ & $\begin{array}{r}15.60 \\
\end{array}$ & & & \begin{tabular}{|r|}
16.35 \\
\end{tabular} & \\
\hline \multirow{2}{*}{7} & 11.35 & 12.10 & 12.85 & 13.60 & 14.35 & 15.10 & \begin{tabular}{|l|}
15.85 \\
\end{tabular} & 16.60 & 17.35 & \begin{tabular}{|l|}
18.10 \\
\end{tabular} & 18.85 \\
\hline & 11.75 & \begin{tabular}{|r|}
12.37 \\
\end{tabular} & 12.98 & \begin{tabular}{|r|}
13.60 \\
\end{tabular} & 14.35 & & \begin{tabular}{|r|}
15.85 \\
\end{tabular} & & \begin{tabular}{|l|}
16.60 \\
\end{tabular} & \begin{tabular}{|r|}
16.60 \\
\end{tabular} & \\
\hline \multirow{2}{*}{8} & 10.85 & 11.60 & 12.35 & 13.10 & 13.85 & 14.60 & 15.35 & 16.10 & 16.85 & \begin{tabular}{|l|}
17.60 \\
\end{tabular} & 18.35 \\
\hline & 12.00 & 12.62 & 3.23 & 13.85 & 14.60 & & \begin{tabular}{|r|}
16.10 \\
\end{tabular} & & 16.85 & 16.85 & 16.1 \\
\hline \multirow{2}{*}{9} & \begin{tabular}{|l|}
10.35 \\
\end{tabular} & 11.10 & 11.85 & 12.60 & 13.35 & 14.10 & \begin{tabular}{|l|}
14.85 \\
\end{tabular} & 15.60 & \begin{tabular}{|l|}
16.35 \\
\end{tabular} & \begin{tabular}{|l|}
17.10 \\
\end{tabular} & 17.85 \\
\hline & 12.25 & 12.87 & 3.48 & \begin{tabular}{|r|}
14.10 \\
\end{tabular} & 14.85 & \begin{tabular}{|r|}
15.60 \\
\end{tabular} & \begin{tabular}{|r|}
16.35 \\
\end{tabular} & $\begin{array}{r}17.10 \\
\end{array}$ & \begin{tabular}{|l|}
17.10 \\
\end{tabular} & \begin{tabular}{|r|}
17.10 \\
\end{tabular} & 16.3 \\
\hline \multirow{2}{*}{10} & 9.10 & 9.85 & 10.60 & 11.35 & 12.10 & 12.85 & 13.60 & \begin{tabular}{|l|l}
14.35 \\
\end{tabular} & 15.10 & \begin{tabular}{|l|l|}
15.85 \\
\end{tabular} & 16.60 \\
\hline & 12.50 & 13.12 & 13.73 & 14.35 & 15.10 & 15.85 & 16.60 & 17.35 & 17.35 & 17.35 & 10.0 \\
\hline
\end{tabular}

The BLUE number on the left is your payoff. The BLACK number on the right is the payoff of each of the other group members when they each invest the amount listed. 


\section{Instructions \\ [ VCM treatments ]}

This is an experiment on decision making. The earnings you receive today will depend on the decisions made by you and by other participants in this room. Please do not talk or communicate with others in any way. If you have a question please raise your hand and an experimenter will come to where you are sitting to answer you in private.

\section{Earnings}

There will be two parts of the experiment. Only one of the two parts will count for payment. Once part 1 and 2 are completed we will flip a coin to determine which part counts for payment. Your earnings in the experiment will be the sum of a $\$ 6$ payment for showing up on time and your earnings from either part 1 or part 2. We will first explain how earnings are determined in part 1 . Once part 1 is completed we will explain how earnings in part 2 are determined. Decisions in part 1 only affect possible earnings in part 1, and decisions in part 2 only affect possible earnings in part 2. Your total earnings will be paid to you in cash and in private at the end of the experiment.

\section{Part 1}

In part 1 you will be matched in groups of four. That is, the computer will randomly match you with three other participants.

You will each have to make one decision, and earnings will depend on the decision made by you and the decisions made by other members of your group. Neither during nor after the experiment will you get to know who the other members of your group are or what decisions they make. Likewise, no one in your group will know who you are and what decision you make.

You and each of the other group members will be given $\$ 8$ and asked to make an investment decision. You may select to invest any dollar amount between $\$ 0$ and $\$ 8$ in a group account. Investments in the group account affect both your earnings and those of the other members of the group. That is, individual earnings depend on the individual investment in the group account and the investment by the other group members.

\section{Decision Screen}

Your investment decision will be made using a decision screen. You make a decision by entering the number of dollars you wish to invest in the group account in the area labeled: Dollars to invest in group account. Once you have made your investment decision, please click the red Finalize Decision button. You will not be able to modify your decision once your choice is finalized. 
A decision screen is shown below. The actual decision screen will include a description of the earnings you and the other group members receive from investing in the group account. Your total earnings will equal the number of dollars you do not invest in the group account ( $\$ 8-$ your investment) plus your earnings from investments in the group account. Earnings from the group account depend on the number of dollars you and the three other members of your group invest in the group account.

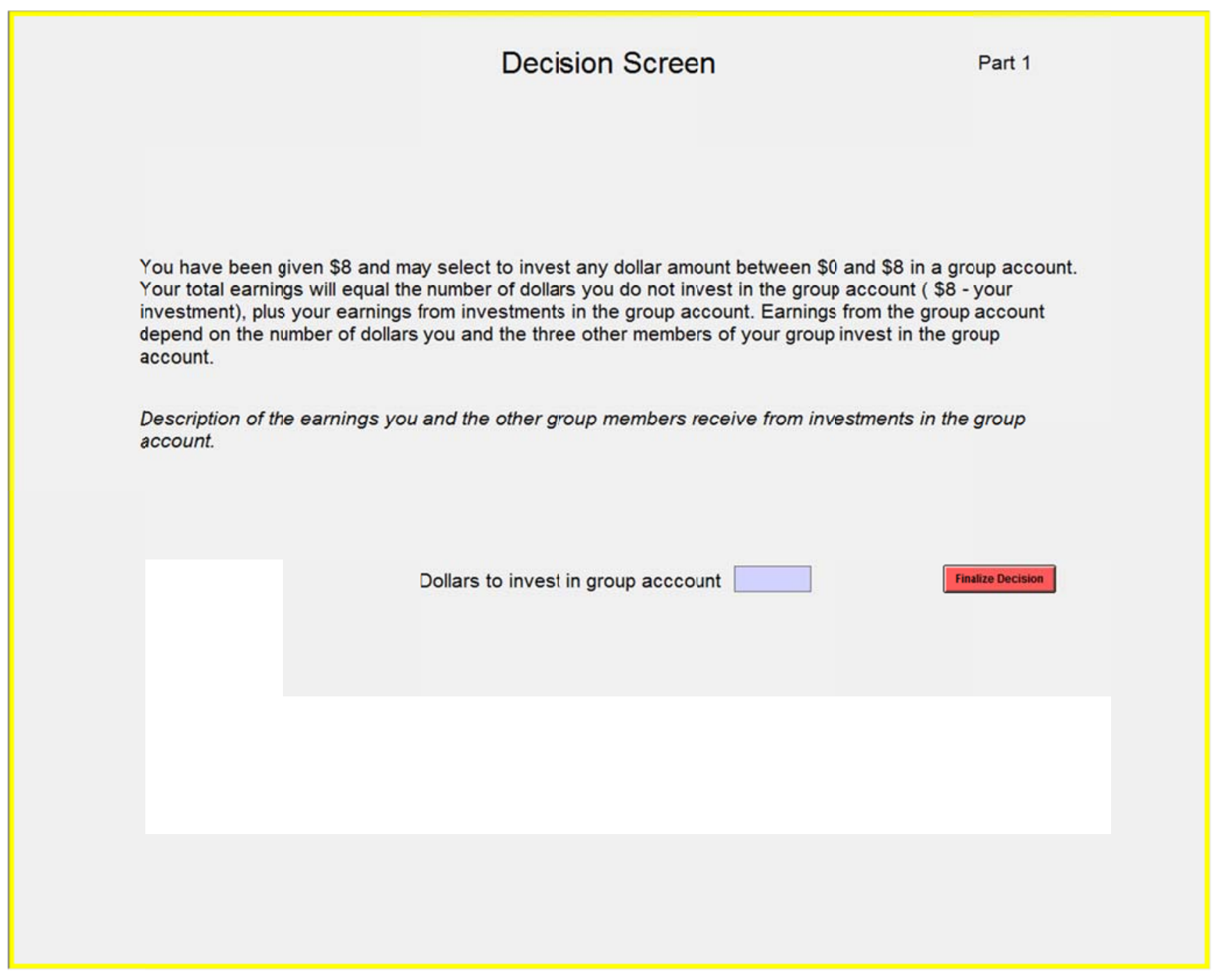

\section{Results Screen}

After everyone has made an investment decision you will see a results screen. The results screen will indicate the investments made by you and the other group members and will summarize the earnings you and the other group members receive if part 1 counts for payment. 


\section{Instructions Part 2}

Part 2 is very similar to part 1 . The only difference is that you now must make investment decisions over a sequence of ten rounds. At the beginning of each round you will be randomly matched with three other people to form a new group of four. You will never be matched with the same three people twice in a row. It is also unlikely that you will meet the same set of three other group members twice. You will not get to know who the other members of your group are nor will you be informed of their past investment. Likewise, no one will know who you are and what investments you made in the past.

Just as for part 1 you will be presented with a decision screen, which reports the earnings that you and the other group members get from investing in the group account. The decision screen will be the same in each round. That is, the earnings are the same for each of the ten rounds and are identical to those seen in part 1.

After each round is complete you will be shown a result screen which reports the investments made by you and the other group members in that round, as well as the earnings you and the other group members made in that round.

If part 2 is selected for payment we will randomly select a number between one and ten. The earnings for the corresponding round will be paid to the participants along with the $\$ 6$ show up fee. The part that counts for payment will be determined by the flip of a coin. The round that counts in part 2 will be determined by having a participant draw a number between 1 and 10 . 


\section{Description of payoffs: Low- and High-VCM treatments}

Low-VCM treatment:

"Every dollar invested in the group account by you or any other member of your group will secure the group a payoff of $\$ 2$ which is divided equally between you and the three other group members. Thus, for every dollar any group member invests in the group account you and each of the other group members will receive 50 cents."

High-VCM treatment:

Same as Low-VCM treatment + "In addition, you will get a bonus of 60 cents for every dollar you personally invest in the group account."

High-VCM 2 treatment:

Same as High-VCM treatment + "That is, you will get a total of $\$ 1.10$ for every dollar you invest in the group account." 
Table A3 Payoff table Low-Interior treatment

Average investment made by the other group members

\begin{tabular}{|c|c|c|c|c|c|c|c|c|c|c|c|}
\hline & 0 & 1 & 2 & 3 & 4 & 5 & 6 & 7 & 0 & 9 & 10 \\
\hline \multirow{2}{*}{0} & 10.00 & 10.75 & 11.50 & 2.25 & 3.00 & 13.75 & 14.50 & 15.25 & 16.00 & 16.75 & 16.30 \\
\hline & 10.00 & 11.95 & 13.90 & 15.85 & 16.10 & 16.35 & 16.60 & 16.85 & & 16.85 & \\
\hline \multirow{2}{*}{1} & \begin{tabular}{l|}
.45 \\
\end{tabular} & 12.20 & 12.95 & 13.70 & 14.45 & 15.20 & 15.95 & 16.70 & 17.45 & 18.20 & 17.75 \\
\hline & 10.25 & 12.20 & 14.15 & 16.10 & 16.35 & 16.60 & 16.85 & 17.10 & 17.10 & $\begin{array}{r}17.10 \\
\end{array}$ & 14.5 \\
\hline \multirow{2}{*}{2} & 12.90 & 13.65 & 14.40 & 15.15 & 15.90 & 16.65 & 17.40 & 18.15 & 18.90 & 19.65 & 19.20 \\
\hline & 10.50 & 12.45 & 14.40 & 16.35 & 16.60 & 16.85 & 17.10 & 17.35 & 17.35 & 17.35 & 14 \\
\hline \multirow{2}{*}{3} & \begin{tabular}{|l|}
14.35 \\
\end{tabular} & 15.10 & 15.85 & 16.60 & 17.35 & 18.10 & 18.85 & 19.60 & 20.35 & 21.10 & 20.65 \\
\hline & 10.75 & 12.70 & 14.65 & \begin{tabular}{|r|}
16.60 \\
\end{tabular} & 16.85 & \begin{tabular}{|l|}
17.10 \\
\end{tabular} & \begin{tabular}{|r|}
17.35 \\
\end{tabular} & 17.60 & \begin{tabular}{|l|}
17.60 \\
\end{tabular} & \begin{tabular}{|l|}
17.60 \\
\end{tabular} & 15.0 \\
\hline \multirow{2}{*}{4} & 14.10 & 14.85 & 15.60 & 16.35 & 17.10 & \begin{tabular}{|l|}
17.85 \\
\end{tabular} & \begin{tabular}{|l|}
18.60 \\
\end{tabular} & 19.35 & 20.10 & \begin{tabular}{|l|}
20.85 \\
\end{tabular} & 20.40 \\
\hline & 11.00 & 12.95 & 14.90 & 16.85 & \begin{tabular}{|r|}
17.10 \\
\end{tabular} & \begin{tabular}{|l|}
17.35 \\
\end{tabular} & \begin{tabular}{|r|}
17.60 \\
\end{tabular} & 17.85 & 17.85 & \begin{tabular}{|r|}
17.85 \\
\end{tabular} & 15.3 \\
\hline \multirow{2}{*}{5} & 13.85 & 14.60 & \begin{tabular}{|l|}
15.35 \\
\end{tabular} & 16.10 & 16.85 & 17.60 & 18.35 & 19.10 & 19.85 & 20.60 & 20.15 \\
\hline & 11.25 & 13.20 & 15.15 & \begin{tabular}{|r|}
17.10 \\
\end{tabular} & \begin{tabular}{|l|}
17.35 \\
\end{tabular} & \begin{tabular}{|l|}
17.60 \\
\end{tabular} & \begin{tabular}{|l|}
17.85 \\
\end{tabular} & 18.10 & \begin{tabular}{|r|}
18.10 \\
\end{tabular} & \begin{tabular}{|r|}
18.10 \\
\end{tabular} & 15.5 \\
\hline \multirow{2}{*}{6} & 13.60 & 14.35 & 15.10 & \begin{tabular}{|l|}
15.85 \\
\end{tabular} & \begin{tabular}{|l|}
16.60 \\
\end{tabular} & \begin{tabular}{|l|l}
17.35 \\
\end{tabular} & 18.10 & 18.85 & 19.60 & \begin{tabular}{|l|}
20.35 \\
\end{tabular} & 19.90 \\
\hline & 11.50 & 13.45 & $\begin{array}{r}15.40 \\
\end{array}$ & 17.35 & $\begin{array}{r}17.60 \\
\end{array}$ & \begin{tabular}{|r|}
17.85 \\
\end{tabular} & \begin{tabular}{|r|}
18.10 \\
\end{tabular} & 18.35 & & \begin{tabular}{|r|}
18.35 \\
\end{tabular} & \\
\hline \multirow{2}{*}{7} & 13.35 & 14.10 & 14.85 & 15.60 & 16.35 & 17.10 & 17.85 & 18.60 & 19.35 & 20.10 & 19.65 \\
\hline & 11.75 & 13.70 & 15.65 & 17.60 & 17.85 & 18.10 & 18.35 & 18.60 & 18.60 & 18.60 & 16.0 \\
\hline \multirow{2}{*}{8} & 12.85 & 13.60 & 14.35 & \begin{tabular}{|l|l|}
15.10 \\
\end{tabular} & 15.85 & 16.60 & 17.35 & 18.10 & 18.85 & \begin{tabular}{|l|}
19.60 \\
\end{tabular} & 19.15 \\
\hline & $\begin{array}{r}12.00 \\
\end{array}$ & 3.95 & 5.90 & 17.85 & 18.10 & 18.35 & 18.60 & 18.85 & 18.85 & 18.85 & 16 \\
\hline \multirow{2}{*}{9} & \begin{tabular}{|l|}
12.35 \\
\end{tabular} & 13.10 & 13.85 & 14.60 & 15.35 & 16.10 & 16.85 & 17.60 & 18.35 & \begin{tabular}{|l|}
19.10 \\
\end{tabular} & 18.65 \\
\hline & 12.25 & 4.20 & 16.15 & 18.10 & 18.35 & 18.60 & 18.85 & 19.10 & 19.10 & 19.10 & 16.5 \\
\hline \multirow[t]{2}{*}{10} & 10.10 & 10.85 & 11.60 & 12.35 & 13.10 & 13.85 & 14.60 & 15.35 & 16.10 & 16.85 & 16.40 \\
\hline & 12.10 & 14.05 & 16.00 & 17.95 & 18.20 & 18.45 & 18.70 & 18.95 & 18.95 & 18.95 & \\
\hline
\end{tabular}

The BLUE number on the left is your payoff. The BLACK number on the right is the payoff of each of the other group members when they each invest the amount listed. 
Table A4. Payoff table High-Interior treatment

Average investment made by the other group members

\begin{tabular}{|c|c|c|c|c|c|c|c|c|c|c|c|}
\hline & 0 & 1 & 2 & 3 & 4 & 5 & 6 & 7 & 8 & 9 & 10 \\
\hline \multirow{2}{*}{0} & 10.00 & 10.75 & 11.50 & 12.25 & 13.00 & 13.75 & 14.50 & 15.25 & 16.00 & 16.75 & 16.30 \\
\hline & 10.00 & 10.62 & 11.23 & 11.85 & 12.60 & 13.35 & 14.10 & 14.85 & 14.85 & 14.85 & 14.30 \\
\hline \multirow{2}{*}{1} & 10.12 & 10.87 & 11.62 & 12.37 & 13.12 & 13.87 & 14.62 & 15.37 & 16.12 & 16.87 & 16.42 \\
\hline & 10.25 & 10.87 & 11.48 & 12.10 & 12.85 & 13.60 & 14.35 & 15.10 & 15.10 & 15.10 & 14.55 \\
\hline \multirow{2}{*}{2} & \begin{tabular}{|l|}
10.23 \\
\end{tabular} & 10.98 & 11.73 & 12.48 & 13.23 & 13.98 & 14.73 & 15.48 & 16.23 & 16.98 & 16.53 \\
\hline & 10.50 & 11.12 & 11.73 & 12.35 & 13.10 & 13.85 & 14.60 & 15.35 & 15.35 & 15.35 & 14.80 \\
\hline \multirow{2}{*}{3} & 10.35 & 11.10 & 11.85 & 12.60 & 13.35 & 14.10 & 14.85 & 15.60 & 16.35 & 17.10 & 16.65 \\
\hline & 10.75 & 11.37 & 11.98 & 12.60 & 13.35 & 14.10 & 14.85 & 15.60 & 15.60 & 15.60 & 15.05 \\
\hline \multirow{2}{*}{4} & \begin{tabular}{|l|}
10.60 \\
\end{tabular} & 11.35 & 12.10 & 12.85 & 13.60 & 14.35 & 15.10 & 15.85 & 16.60 & 17.35 & 16.90 \\
\hline & 11.00 & 11.62 & 12.23 & 12.85 & 13.60 & 14.35 & 15.10 & 15.85 & 15.85 & 15.85 & 15.30 \\
\hline \multirow{2}{*}{5} & 10.85 & 11.60 & 12.35 & 13.10 & 13.85 & 14.60 & 15.35 & 16.10 & 16.85 & 17.60 & 17.15 \\
\hline & 11.25 & 11.87 & 12.48 & 13.10 & 13.85 & 14.60 & 15.35 & 16.10 & 16.10 & 16.10 & 15.55 \\
\hline \multirow{2}{*}{6} & \begin{tabular}{|l|l|}
11.10 \\
\end{tabular} & 11.85 & 12.60 & 13.35 & 14.10 & 14.85 & 15.60 & 16.35 & 17.10 & 17.85 & 17.40 \\
\hline & 11.50 & 12.12 & 12.73 & 13.35 & 14.10 & 14.85 & 15.60 & 16.35 & 16.35 & 16.35 & 15.80 \\
\hline \multirow{2}{*}{7} & 11.35 & 12.10 & 12.85 & 13.60 & 14.35 & 15.10 & 15.85 & 16.60 & 17.35 & 18.10 & 17.65 \\
\hline & 11.75 & 12.37 & 12.98 & 13.60 & 14.35 & 15.10 & 15.85 & 16.60 & 16.60 & 16.60 & 16.05 \\
\hline \multirow{2}{*}{8} & 10.85 & 11.60 & 12.35 & 13.10 & 13.85 & 14.60 & 15.35 & 16.10 & 16.85 & 17.60 & 17.15 \\
\hline & 12.00 & 12.62 & 13.23 & 13.85 & 14.60 & 15.35 & 16.10 & 16.85 & 16.85 & 16.85 & 16.30 \\
\hline \multirow{2}{*}{9} & 10.35 & 11.10 & 11.85 & 12.60 & 13.35 & 14.10 & 14.85 & 15.60 & 16.35 & 17.10 & 16.65 \\
\hline & 12.25 & 12.87 & 13.48 & 14.10 & 14.85 & 15.60 & 16.35 & 17.10 & $\begin{array}{r}17.10 \\
\end{array}$ & $\begin{array}{r}17.10 \\
\end{array}$ & 16.55 \\
\hline \multirow{2}{*}{10} & \begin{tabular}{|l|l}
10.10 \\
\end{tabular} & 10.85 & 11.60 & 12.35 & 13.10 & 13.85 & 14.60 & 15.35 & 16.10 & \begin{tabular}{|l|}
16.85 \\
\end{tabular} & 16.40 \\
\hline & 12.10 & 12.72 & 13.33 & 13.95 & 14.70 & 15.45 & 16.20 & 16.95 & 16.95 & 16.95 & 16.40 \\
\hline
\end{tabular}

The BLUE number on the left is your payoff. The BLACK number on the right is the payoff of each of the other group members when they each invest the amount listed. 